\title{
The Effect of Grid Spacing and Domain Size on the Quality of Ensemble Regional Climate Downscaling over South Asia during the Northeasterly Monsoon
}

\author{
JiAN-HUA QIAN AND LAREEF ZUBAIR \\ International Research Institute for Climate and Society, Columbia University, Palisades, New York
}

(Manuscript received 11 August 2009, in final form 9 February 2010)

\begin{abstract}
The performance of an ensemble-based dynamical regional climate downscaling system is evaluated over southern Asia in a northeasterly monsoon season for different choices in grid spacing and domain size. A seven-member ensemble of the ECHAM4.5 global climate model at a resolution of about 300-km grid size was used to drive the RegCM3 regional climate model with grid sizes of 100, 50, 25, and $20 \mathrm{~km}$, respectively. The performance is reported in detail over Sri Lanka. Two sets of regional model runs were undertaken to assess the effect of grid spacing and model domain size on the downscaling performance. The RegCM3 simulation with $100-\mathrm{km}$ grid size significantly underestimates the height of the central mountain range in Sri Lanka, in a manner that is too coarse to capture orographic influences on the rainfall. However, the RegCM3 simulations with grid sizes from 20 to $50 \mathrm{~km}$ capture mesoscale features that arise from uplift condensation on the windward side of the monsoon winds due to the topography. These simulations also capture the orographic influences on the month-to-month rainfall over Sri Lanka that were absent in the ECHAM4.5. While the "small domain" runs [where only the forcings for the region immediately around Sri Lanka $\left(4^{\circ}-11^{\circ} \mathrm{N}, 76^{\circ}-85^{\circ} \mathrm{E}\right)$ are used] are computationally more efficient, the results are overly controlled by the lateral boundary driving of the ECHAM4.5 so they inherit large uncertainty from the seven ECHAM4.5 realizations used for the RegCM3 ensemble runs. The "large domain" simulation used a domain comprising both land and ocean (approximately $4^{\circ} \mathrm{S}-22^{\circ} \mathrm{N}, 65^{\circ}-96^{\circ} \mathrm{E}$ ). The large-domain group of simulations produced reasonable spatial distribution of precipitation over the region. Moreover, the ensemble spread was considerably reduced in the large-domain high-resolution runs. Therefore, fine enough grid resolution ( $25 \mathrm{~km}$ or less) and sufficiently large domain size are both needed to simulate the essential features of precipitation in this tropical and monsoonal region.
\end{abstract}

\section{Introduction}

Weather and climate on the earth have been simulated using computers with atmospheric and oceanic numerical models with a domain that covers the globe or a limited region on it. Climate in a particular area is not only determined by the regional meteorological forcings but is also affected by its interactions with larger-scale phenomenon and a global domain is needed to capture these interactions. Contemporary general circulation models (GCMs) used for operational seasonal climate prediction typically use a coarse resolution with grid size of about $100-500 \mathrm{~km}$ because of limited computational resources. Quite often such coarse resolution is of limited use for

Corresponding author address: Dr. Jian-Hua (Joshua) Qian, International Research Institute for Climate and Society, The Earth Institute at Columbia University, Lamont Campus, 61 Route 9W, Palisades, NY 10964-8000.

E-mail: jqian@iri.columbia.edu practical applications such as for health, water resources, agriculture, and disaster risk management. To mitigate this problem, regional climate models with higher resolution (10-100-km grids) may be driven by the output of the GCMs, over the area of interest. Regional models can recover some of the important regional-scale features underestimated in coarse-resolution GCMs such as the influence of topography on the atmosphere (Dickinson et al. 1989; Laprise et al. 2008) and the local thermally driven land-sea breezes (Qian 2008). Regional climate models are driven by time-dependent large-scale meteorological fields specified at the boundaries of the chosen domain. The choice of domain affects the balance between the boundary and internal model forcings in the simulation (Anthes et al. 1989; Giorgi and Mearns 1999). The location of boundaries in relation to the regional sources of forcings in a particular climatic regime can also affect the regional climate model simulations (Seth and Giorgi 1998; Rauscher et al. 2006). 
Unlike deterministic weather forecasts, a seasonal and longer-term climate prediction is usually represented by a probabilistic distribution over a range of outcomes to account for the relatively large uncertainties associated with (i) the chaotic nature of the nonlinear climate system (Lorenz 1963); (ii) the errors in observation that are used as input to forecast models; (iii) the model deficiencies in representation of physical and biochemical processes, especially subgrid-scale processes; and (iv) the limitation of numerical schemes in the discretion of continuous equations in the computer models, such as the finitedifference or spectral methods in global models, or the lateral boundary nesting method in regional models (Sun et al. 2006). The uncertainties become larger when the spatial scale becomes smaller. Multimember ensemble modeling, which is used as a mean to represent those uncertainties numerically, has been extensively studied for GCMs (Palmer et al. 2005), but not adequately for regional climate models.

In this paper, we evaluated the uncertainties of regional model simulations associated with ensemble global model forcing, and the choice of regional model domain sizes and grid spacing, for Sri Lanka and the surrounding region in South Asia during the northeasterly monsoon season. This work is undertaken in a tropical region with ocean and land influences, complex topography, and monsoon influences which will challenge any downscaling exercise.

Societal vulnerability to climate variability is greater in the tropics, but there is also greater seasonal climate predictability in the tropics (Mason and Goddard 2001). Thus, the value of skillful predictions from regional climate models is enhanced for the tropics. Previously work on regional climate models has been undertaken for the tropical South America region (e.g., Qian et al. 2003; Roads et al. 2003; Seth et al. 2004; Sun et al. 2006), the North America region (e.g., Giorgi et al. 1993a,b; Qian et al. 1999), the East Asian monsoon region (e.g., Qian et al. 2004; Leung et al. 1999), the eastern African region (e.g., Sun et al. 1999), the Indian summer monsoon region (e.g., Bhaskaran et al. 1996), and the Southeast Asian monsoon region (e.g., Qian 2008; Moron et al. 2010).

McGregor (1997) briefly reviewed general concepts and methodologies of regional climate modeling, such as nesting methods, conservation properties, orographic effect, and the usage of regional climate models in simulation of present-day climate and climate change. Wang et al. (2004) reviewed the progress and challenges in regional climate modeling, including methodologies, physical process studies, and the internal variability and uncertainty for downscaled seasonal climate predictions and climate change studies. Pal et al. (2007) introduced a network of regional climate modeling and application for developing countries based on a regional climate model (RegCM3) developed by the Abdus Salam International Centre for Theoretical Physics (ICTP). Alexandru et al. (2007), Laprise (2008), and Laprise et al. (2008) clarified some key issues faced by the regional climate modeling community from a Canadian perspective based on analyses of a series of the Big Brother Experiments, in which a small-domain regional climate model (the little brother) is driven by the somewhat filtered outputs from the same regional model with a large domain (the big brother) to examine the capacity of the little brother to recover small-scale features in the original unfiltered data in the big brother.

Sri Lanka is an island with an east-west width of $224 \mathrm{~km}$ and north-south length of $432 \mathrm{~km}$ (Fig. 1), located within the monsoon region (Ramage 1971). A mountain range runs north to south in the middle of the country, with a narrow peak at $2532 \mathrm{~m}$ above sea level. Sri Lanka and southern India and the surrounding region has a complex topography including islands, subcontinent, straits, and the ocean.

While most of south Asia receives its rainfall during the boreal summer, the region of southern India and Sri Lanka receives most of its rainfall from October to December. Previous regional climate modeling exercises for south Asia have focused primarily on the summer season. Assessing the quality of climate simulations and associated uncertainties over this region is of importance since it not only affects 140 million people but can also be useful given the relative skill in predictability of GCMs over this region (Mason and Goddard 2001; Goddard et al. 2003; Li et al. 2008). We focus on Sri Lanka given the availability of finescale data. This work shall also benefit ongoing use of climate information for risk management in the health (Zubair et al. 2008), agriculture (Zubair 2002; Peiris et al. 2008), water resources (Chandimala and Zubair 2006), and disaster management sectors (Lyon et al. 2009).

The objectives of this paper are 1) to examine whether high-resolution downscaling with regional models adds value over the GCM simulation over Sri Lanka; and 2) to explore sources of uncertainties in the ensemble downscaling: both from the global model due to the ensemble spread in the large-scale forcing, or from the regional model due to constraints on model grid spacing and domain size.

The global and regional models and experimental designs are described in section 2. Observational data used to check the fidelity of model simulation are described in section 3. Sensitivities of simulated rainfall distribution to domain size and grid spacing are analyzed in section 4 . The uncertainty as represented by the ensemble spread (the variance among the ensemble members) and its sensitivity to domain size and grid spacing are studied in section 5. Conclusions are drawn in section 6 . 
(a) ECHAM4.5 T42 terrain (300km-grid)

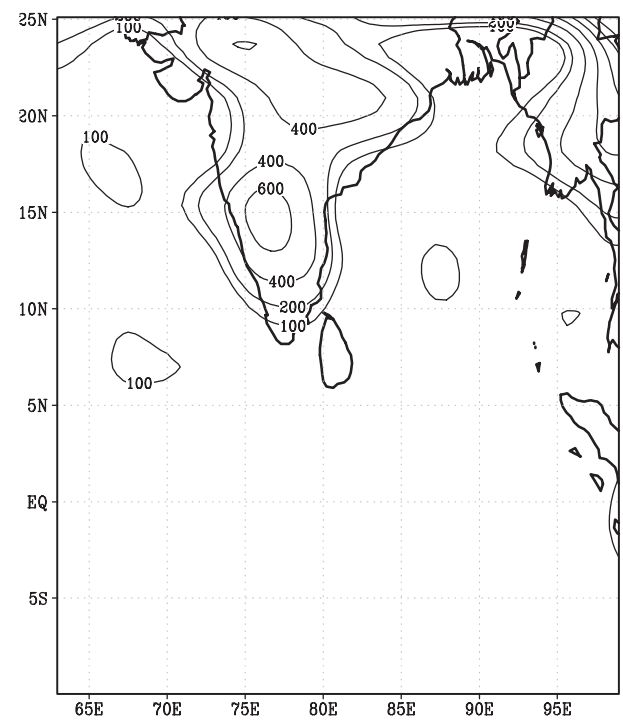

(c) RegCM3 $20 \mathrm{~km}$-grid domain and terrain

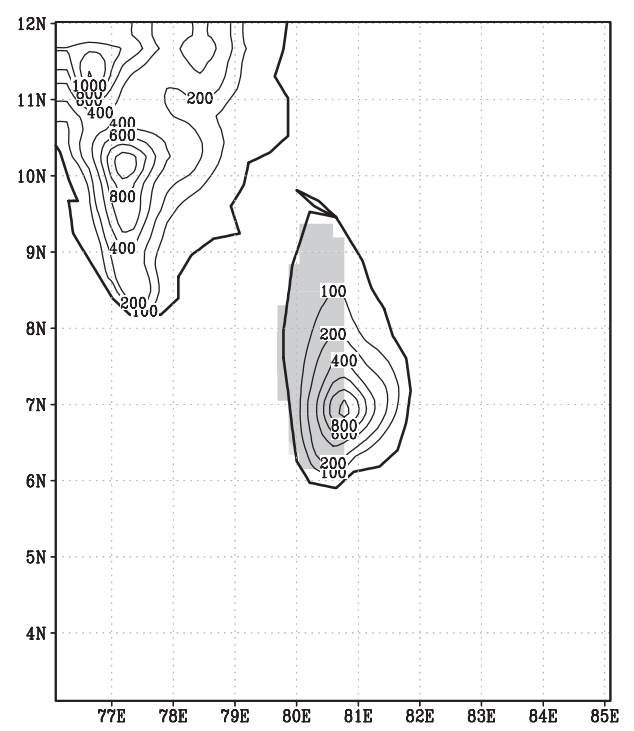

(b) RegCM3 $100 \mathrm{~km}$-grid domain and terrain

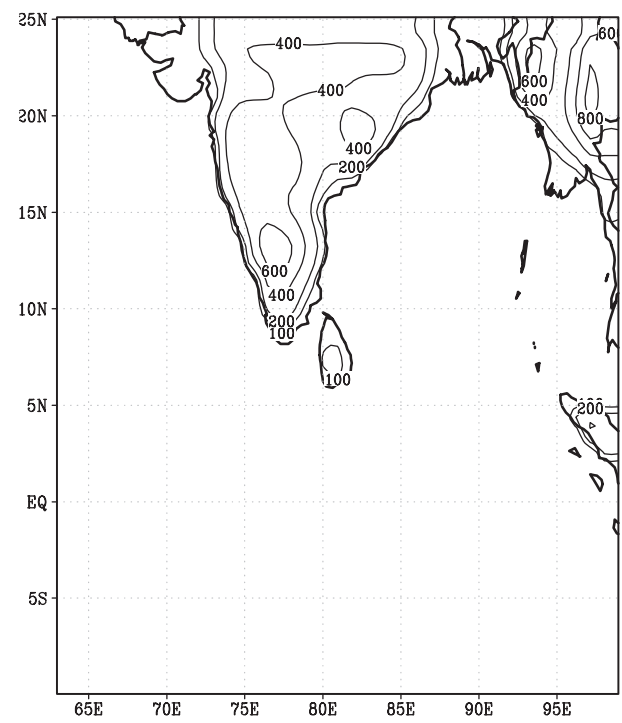

(d) USGS observed 2 -min terrain (2km-grid)

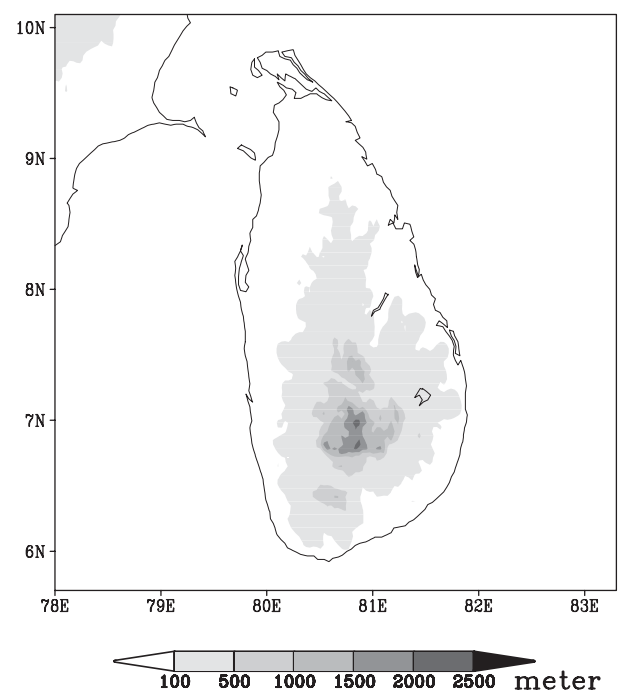

FIG. 1. (a) Terrain heights (m) in south Asia in ECHAM4.5 T42 (about 2.8 or 300-km grid size), (b) domain and terrain heights in RegCM3 with grid size of $100 \mathrm{~km}$, (c) domain and terrain heights in RegCM3 with grid size of $20 \mathrm{~km}$ (shaded area denotes western Sri Lanka), and (d) the USGS observed terrain heights (shaded) on 2-min grids (about 2-km grid size) over Sri Lanka.

\section{Models and experimental design}

The atmospheric GCM ECHAM4.5 (Roeckner et al. 1996) with T42 horizontal resolution and 19 vertical levels is used for seasonal and interannual climate prediction at the International Research Institute for Climate and Society (IRI; Barnston et al. 2003; Li et al. 2008). Its resolution of about $300-\mathrm{km}$ grid $\left(2.8125^{\circ}\right)$ is too coarse to capture the topographic features of Sri Lanka (Fig. 1a).
The regional climate model, RegCM3, was used to downscale the results from the ECHAM4.5 model to a smaller and larger domain and to grid sizes ranging from 100 to $20 \mathrm{~km}$.

The ECHAM4.5 is an atmospheric global spectral model based on the Navier-Stokes equations of the atmosphere with a hydrostatic approximation in the vertical. The prognostic variables are vorticity, divergence, surface pressure, temperature, specific humidity, and mixing ratio 
TABLE 1. Model simulations, and 6-month-averaged ensemble means and spreads of monthly precipitation (mm day $\left.{ }^{-1}\right)$, and relative ensemble spreads (\%) for Sri Lanka.

\begin{tabular}{lcccccr}
\hline \hline Simulation & Domain size & Grid number & Grid size & Mean & Spread & Relative spread $(\%)$ \\
\hline ECHAM & Global & & $300 \mathrm{~km}$ & 1.36 & 0.42 & 31 \\
L100 & Large & $40 \times 40$ & $100 \mathrm{~km}$ & 3.20 & 0.48 & 15 \\
L50 & Large & $80 \times 80$ & $50 \mathrm{~km}$ & 3.18 & 0.33 & 11 \\
L25 & Large & $160 \times 160$ & $25 \mathrm{~km}$ & 3.64 & 0.33 & 9 \\
S50 & Small & $20 \times 20$ & $50 \mathrm{~km}$ & 4.56 & 1.19 & 26 \\
S25 & Small & $40 \times 40$ & $25 \mathrm{~km}$ & 4.56 & 1.09 & 24 \\
S20 & Small & $50 \times 50$ & $20 \mathrm{~km}$ & 4.41 & 1.04 & 24 \\
\hline
\end{tabular}

of total cloud water. To account for the inherent uncertainties in the nonlinear climate system, seven members of the Atmospheric Model Intercomparison Project (AMIP) run (forced by observed sea surface temperature) are used to drive the regional climate model RegCM3.

The regional climate model RegCM3 was developed by the Physics of Weather and Climate Group at the ICTP, at Trieste, Italy, and is based upon RegCM2 (Giorgi et al. 1993a,b). Its dynamical core is close to that of the hydrostatic version of the fifth-generation Pennsylvania State University-National Center for Atmospheric Research Mesoscale Model (MM5), a gridpoint model (with Arakawa-B grid) based on primitive atmospheric equations. The model uses a pressure-based terrain-following $\sigma$ coordinate:

$$
\sigma=\frac{p-P_{t}}{P_{s}-P_{t}},
$$

where $p$ is the air pressure in the atmosphere, $P_{s}$ is the surface air pressure, and $P_{t}$ is a prescribed constant pressure at the model top.

The regional model is driven by lateral boundary conditions derived from 6-hourly outputs of the GCM. To avoid discrepancies between the outer driving fields and the model internal physics, an exponential relaxation scheme (Giorgi et al. 1993b; Qian et al. 2003) is applied to a lateral buffer zone with a width of five grid intervals. The relaxation scheme consists of Newtonian and diffusion terms that are added to the model tendency equations for wind components, temperature, water vapor mixing ratio, and surface pressure.

The regional model is totally governed by its own physics in the inner domain surrounded by the lateral buffer zone, and is only subject to external forcing by the lower boundary of land and ocean. Over land area, the Biosphere-Atmosphere Transfer Scheme (BATS; Dickinson et al. 1993) is employed to compute surface radiative, sensible, and latent heat; momentum fluxes; surface temperature; and moisture based on the assigned vegetation and soil parameters. Over the ocean, the model is forced by the sea surface temperature (SST) data obtained from spatial and temporal interpolation of observed monthly gridded SST data. The large-scale cloud and precipitation process is calculated by the subgrid cloud scheme of Pal et al. (2000) in which each grid cell is partitioned into a cloudy and noncloudy fraction according to the averaged relative humidity. The Grell cumulus scheme with Fritsch-Chapell closure (Grell 1993) is used to calculate the precipitation due to moist convection. The parameterization scheme of the diabatic heating by solar and terrestrial radiation is that of the NCAR Community Climate Model (CCM3; Kiehl et al. 1996). Finally, the parameterizations representing subgridscale processes in the planetary boundary layer, such as turbulent transfer of momentum and heat in the lower atmosphere are those of Holtslag et al. (1990).

The RegCM3 was run over southern south Asia with different grid sizes of $100,50,25$, and $20 \mathrm{~km}$, with its domain and topography shown in Fig. $1 \mathrm{~b}$ (100-km grid) and Fig. 1c (20-km grid), respectively. The RegCM3 simulations performed are listed in Table 1. The domains are centered over Sri Lanka at $7.5^{\circ} \mathrm{N}, 80.5^{\circ} \mathrm{E}$. Three experiments use a small domain (about $1000 \mathrm{~km} \times 1000 \mathrm{~km}$ ) with grid sizes of 50,25 , and $20 \mathrm{~km}$, denoted by S50, S25, and S20, respectively. The other three experiments use a large domain (about $4000 \mathrm{~km} \times 4000 \mathrm{~km}$ ) with grid sizes of 100,50 , and $25 \mathrm{~km}$, denoted by L100, L50, and L25, respectively. The fine-resolution simulations are computationally expensive; for example, the $20-\mathrm{km}$ grid run would be $5^{3}=125$ times more expensive in terms of computational cost than the $100-\mathrm{km}$ grid run.

Vannitsem and Chome (2005) tested sensitivity of regional climate modeling results to domain sizes over a midlatitude region in western Europe. They found that the domain sizes need to reach a certain extent $\left(43^{\circ}\right.$ in the midlatitudes, which is about $2000-3000 \mathrm{~km}$ across) to obtain good-quality simulation of the model variables. Leduc and Laprise (2009) ran the Canadian regional climate model in North America in winter and found that small domain models effectively retain time-averaged (stationary) forcing from the driving field, while large domain models generate more small-scale transient-eddy variability in the interior of the domain. Using a regional 
climate model driven by analyses, Seth and Giorgi (1998) found that the smaller domain captures observed summer rainfall in the central United States better than the larger domain, probably because of the stronger forcing from the analyses in the smaller domain. The small-domain simulations are reexamined here in the context of a GCM-driving ensemble modeling perspective. Considering the trade-off between large domain size and fine resolution (e.g., the L25 is very expensive), we chose our large domain with a size of about $3000-4000 \mathrm{~km}$ across (corresponding to D4 or D5 in Vannitsem and Chome 2005). This is probably good enough considering it is in the tropics where winds (and thus lateral forcing) are usually weaker than those in winter in the midlatitudes where the atmospheric baroclinicity is very strong. The small-domain runs are compared to the largedomain runs and examined in the multimember GCMdriving ensemble modeling perspective.

Because of the strong orographic effect on the rainfall in Sri Lanka, an adequate representation of terrain in the regional model is necessary. Figure $1 \mathrm{~b}$ shows that the $100-\mathrm{km}$ grid resolution gives a peak of less than $200 \mathrm{~m}$ for the central mountain and this is insufficient. The $20-\mathrm{km}$ grid shows a central mountain with the peak height slightly over $1000 \mathrm{~m}$ (Fig. 1c), which is a considerable improvement but is still much less than the actual peak of $2532 \mathrm{~m}$. The observed U.S. Geological Survey (USGS) elevation of 2 min or about 2-km grid size over Sri Lanka is shown in Fig. 1d. Note that the area around the highest peak is narrow and steep such that only a tiny area has an elevation higher than $2000 \mathrm{~m}$ (Fig. 1d). The simulated area above $1000 \mathrm{~m}$ is smaller in Fig. 1c than in Fig. 1d. Nevertheless, the 20-km grid (Fig. 1c) captures the gross features of the central mountain range. Note that in a regional climate modeling study over Java Island (which is about $200 \mathrm{~km}$ in width, slightly narrower than Sri Lanka), a 25-km grid RegCM3 simulated landsea breezes and mountain-valley winds reasonably well (Qian 2008). Considering the limitation of the hydrostatic dynamics (discussed in detail in Qian and Kasahara 2003), which is used in the current version of the RegCM3 and possible problems of using the cumulus parameterization schemes at extremely high resolution (because the subgrid convection schemes were designed for mesoscale models with typical grid sizes in tens of kilometers; Grell 1993), we limit our simulation at mesoscale resolution to grid sizes of $20 \mathrm{~km}$ and above. Our goal is to capture the major mesoscale features of orographic rainfall over Sri Lanka.

The regional model has 18 vertical levels with 5 levels in the lowest $1.5 \mathrm{~km}$ of the atmosphere and the top of the model atmosphere is at $100 \mathrm{hPa}\left(P_{t}\right)$. The model was run for 6 months in the largely northeasterly monsoon season from 1 October 2000 to 1 April 2001. The time step for the $100-\mathrm{km}$ grid runs was $200 \mathrm{~s}$ and that for the $20-\mathrm{km}$ run was $40 \mathrm{~s}$.

\section{Observed data}

Three observational datasets of precipitation were used for model evaluation: 1) the Tropical Rainfall Measuring Mission (TRMM) satellite rainfall estimation $\left(0.25^{\circ} \times\right.$ $0.25^{\circ}$ grid) (Kummerow et al. 2001), which has been used for tropical climate studies such as for convection and precipitation diurnal cycle studies (Wang et al. 2007; Zhou and Wang 2006) and the terrain effect on the Asian monsoon (Xie et al. 2006); 2) the gridded station observation, on $0.2^{\circ} \times 0.2^{\circ}$ grids covering Sri Lanka developed from observations at 220 observing stations (Lyon et al. 2009), and on $1^{\circ} \times 1^{\circ}$ grids covering India developed by the Indian Meteorological Department (Rajeevan et al. 2005); and 3) the National Centers for Environmental Prediction (NCEP)-NCAR Reanalyses (NNR; Kalnay et al. 1996) wind field was used to validate the simulated atmospheric circulation.

Figure 2 shows the TRMM monthly mean precipitation (in units of $\mathrm{mm} \mathrm{day}^{-1}$ ) and NNR 850-hPa winds during the 2000-01 winter monsoon season. In October 2000, the wind field in the lower atmosphere over southern India and Sri Lanka was still controlled by westerlies, while northern India began to be dominated by northeasterlies indicating a transition from summer to winter monsoon season. The average $850-\mathrm{hPa}$ wind field in this month had a cyclonic circulation over the Bay of Bengal (BOB). In the subsequent months, the maximum rainfall shifted toward the southeast as the winter monsoon progressed. Starting from November, the lower atmosphere over Peninsula India and Sri Lanka were controlled by the northeasterly winds. While northern India received little precipitation, Sri Lanka and the southernmost Indian state (Tamil Nadu) received plenty of rainfall. In December 2000, eastern Tamil Nadu and Sri Lanka continued to receive plenty of rainfall. By January 2001, Tamil Nadu received very little rainfall, but Sri Lanka continued to garner significant rainfall, particularly in the east. In the following two months, the region of high precipitation region shifted farther to the southeast to the eastern Indian Ocean.

Station-based rainfall gridded data over Sri Lanka and India are shown for the period from October to March (Fig. 3). The finescale spatial features in the highresolution station data are not well captured in the TRMM data. The station data show enhanced precipitation on the windward side of the central mountain range of Sri Lanka (i.e., over western slopes in October and over eastern slopes from November 2000 to January 2001). The 

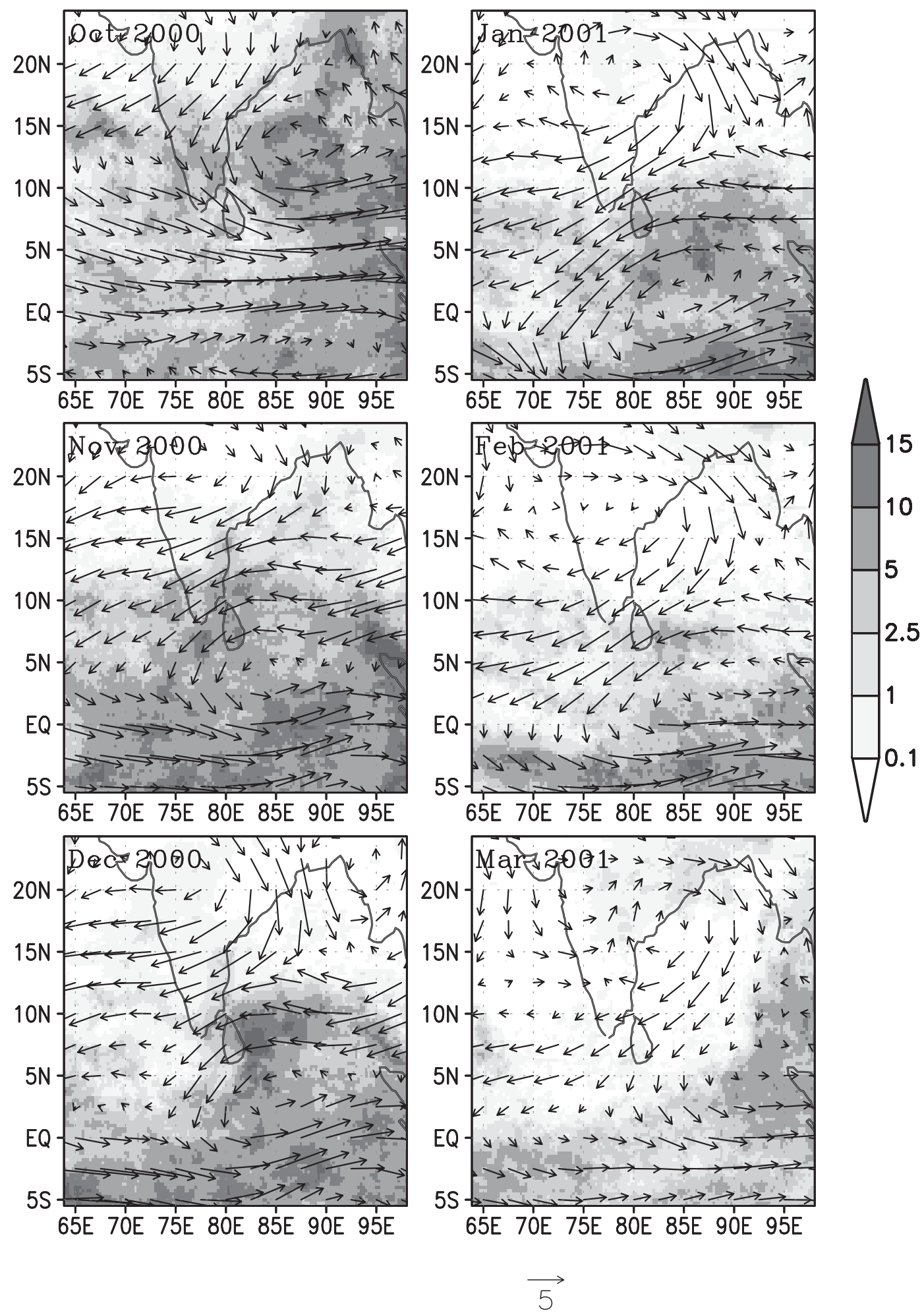

FIG. 2. TRMM monthly precipitation (shaded, $\mathrm{mm} \mathrm{day}^{-1}$ ) and NCEP-NCAR reanalysis $850-\mathrm{hPa}$ winds $\left(\mathrm{m} \mathrm{s}^{-1}\right)$, October 2000-March 2001. 

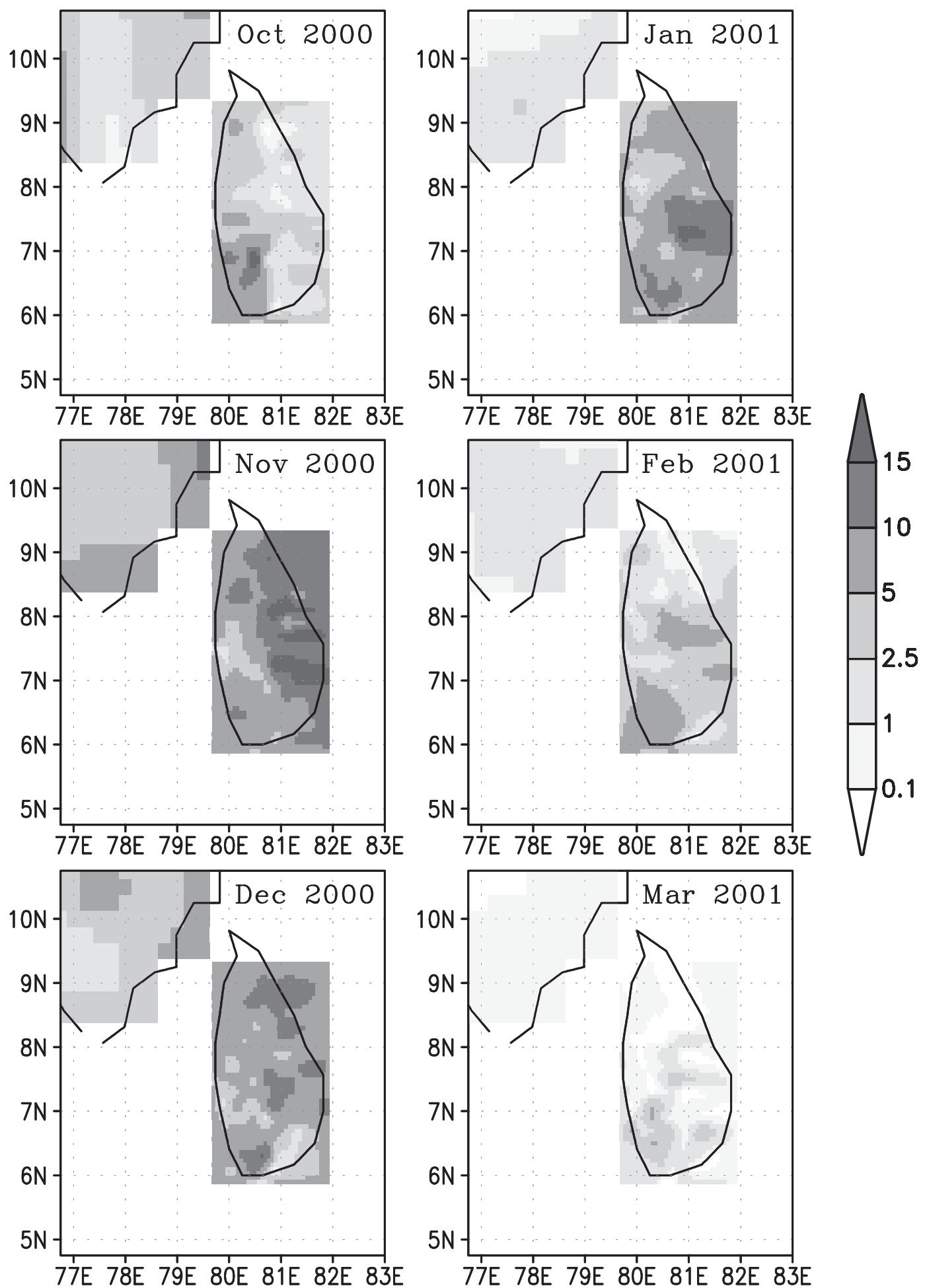

FIG. 3. Station observation of monthly precipitation (shaded, $\mathrm{mm}_{\text {day }}{ }^{-1}$ ) over Sri Lanka and southern India, October 2000-March 2001. 
precipitation over Sri Lanka diminishes from February to March 2001 as the rainfall is shifted to the southeast.

\section{Uncertainties in the spatial heterogeneity of precipitation distribution and winds}

\section{a. Sensitivity of large-scale precipitation and winds to grid spacing}

Figure 4 shows the seven-member ensemble mean of the ECHAM4.5 (Fig. 4b), and RegCM3 large-domain simulations (Figs. 4c-e) for L100, L50, and L25, respectively, for October 2000. The observed TRMM precipitation and NNR winds are plotted in (Fig. 4a) for comparison. In the observations, a region of cyclonic circulation centered at about $\left(13^{\circ} \mathrm{N}, 85^{\circ} \mathrm{E}\right)$ is surrounded by a belt of heavy rainfall. The region of maximum rainfall around the cyclonic circulation extends southeastward to Sumatra in Indonesia and northeastward to another rainfall center at the northern tip of the BOB. The ECHAM4.5 successfully simulated the general feature of rainfall and winds over the region. However, there are some differences between Figs. $4 \mathrm{a}$ and $4 \mathrm{~b}$. The cyclonic circulation and the associated precipitation center simulated by the ECHAM over the northern BOB are displaced north of the observed cyclonic circulation center by at least $5^{\circ}$ of latitude (Fig. 4b).

The 850-hPa circulations in the large-domain simulations of RegCM3 (L100, L50, and L25) are similar to each other; all of these follow the circulation pattern of the driving ECHAM shown in Fig. 4b. The winds near the northeast corner of the domain associated with the cyclonic circulation are stronger both in the ECHAM and RegCM3 runs than in the NNR data. However, the simulated westerlies in the equatorial Indian Ocean in the ECHAM and RegCM3 runs are weaker than those in the reanalyses. In boreal fall, there is a westerly jet over the equatorial Indian Ocean (Wyrtki 1973; Hastenrath and Polzin 2004). The weaker westerly jet in the ECHAM4.5 is probably caused by the underestimation of rainfall over the Maritime Continent of Indonesia, leading to reduction of low-level atmospheric convergence (Qian 2008). The large-scale distributions of precipitation in L100, L50, and L25 are also similar, with heavier precipitation over northern BOB (Figs. 4c-e).

The lack of sensitivity of large-scale features of rainfall and winds to grid sizes of the RegCM3 (as shown in Figs. 4c-e, and in Figs. 5 and 6) is likely due to the following three reasons: 1 ) the RegCM3 is driven by the same set of seven ensemble members of the ECHAM4.5; 2) most of the RegCM3 domain is over ocean and the model is driven by the same set of prescribed SSTs; and 3) the subgrid physics parameterization schemes, especially the cumulus scheme, are basically one dimensional (in the vertical direction) in the RegCM3 (and most other numerical models) at a given time step; thus, it is not very sensitive to horizontal grid spacing. However, as will be shown later, the high-resolution results do have finescale spatial features associated with the mountainous topography.

The ECHAM simulated the transition from summer to winter monsoon season well as seen in the reversal of wind direction (from October to November) and in the southeastward progression of heavy precipitation from the Indian subcontinent to the tropical Indian Ocean. The RegCM3 reproduced this seasonal variation, as shown in the analyses for October 2000 (Fig. 4), December 2000 (Fig. 5), and February 2001 (Fig. 6). Starting from November 2000 (Figs. 2 and 8), the dominant wind direction becomes northeasterly and easterly over Sri Lanka. As examples, Figs. 5 and 6 show the comparison of the monthly mean simulated and observed precipitation and low-level winds for December 2000 and February 2001, respectively. The TRMMobserved precipitation and NNR reanalysis winds (Figs. 5a and 6a) show that the center of maximum precipitation moved to locations to the east and southeast of Sri Lanka during December and February, respectively. Compared to Fig. 5a, the simulated cyclonic circulation at $850 \mathrm{hPa}$ between the equator and $5^{\circ} \mathrm{N}$ over the south Bay of Bengal is reproduced in all large-domain simulations, albeit weaker and shifted slightly to the south. The eastern coast of Tamil Nadu and Sri Lanka received more precipitation than the western side in the simulations for December. The western side of the Indian Peninsula received small amounts of precipitation during December as shown in the TRMM data, but ECHAM produced slightly more precipitation over this area (Fig. 5b). However, the RegCM3 simulations (Figs. 5c-e) seem to estimate lower precipitation over the western side, similar to the observations.

By February 2001, the major rainbelt advances farther to the equatorial Indian Ocean (Fig. 6). The precipitation distribution in the ECHAM run (Fig. 6b) is rather even and zonally oriented, and is quite different from the TRMM observation. The RegCM3 simulations (L100, L50, and L25) produced very little precipitation (less than $0.1 \mathrm{~mm} \mathrm{day}^{-1}$ ) over the northern and northwestern part of the domain, corresponding well with the TRMM observation, and improving upon the precipitation produced by the GCM.

\section{b. Sensitivity of local finescale precipitation to grid spacing and domain size}

To analyze the topographic effect on the finescale spatial features of precipitation, the precipitation and 
(a) TRMM rain \& NNR winds

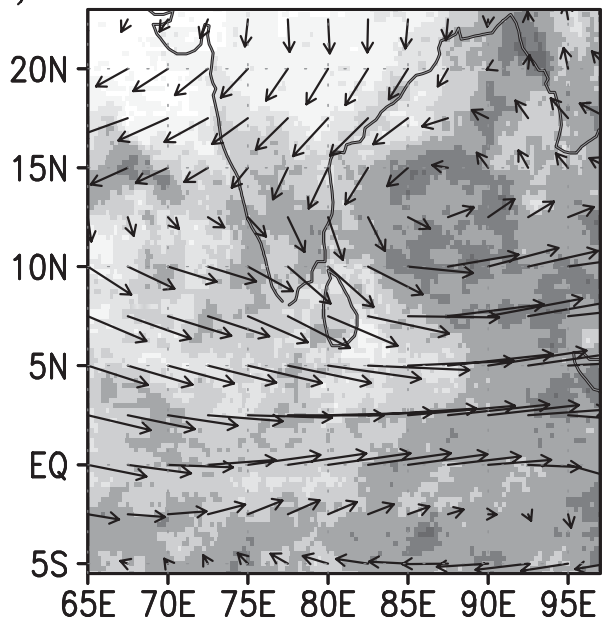

(c) L100

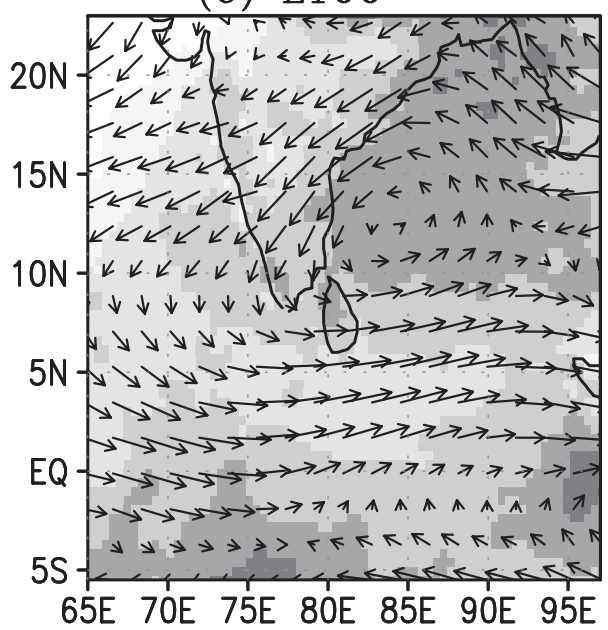

(e) L25

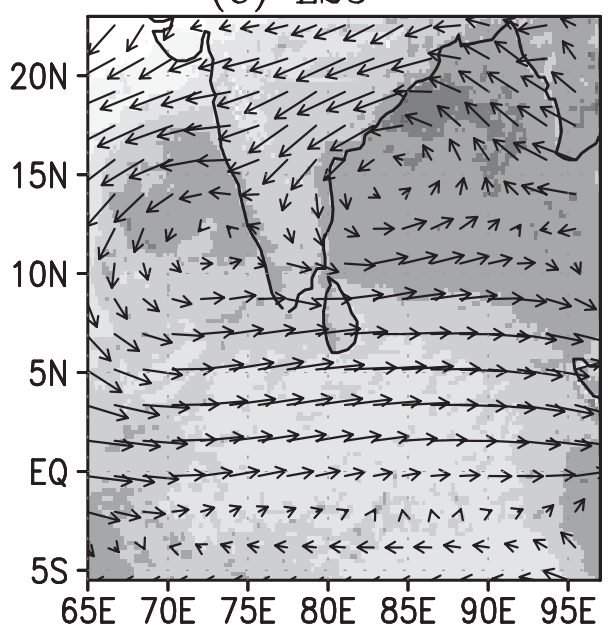

(b) ECHAM4.5 T42

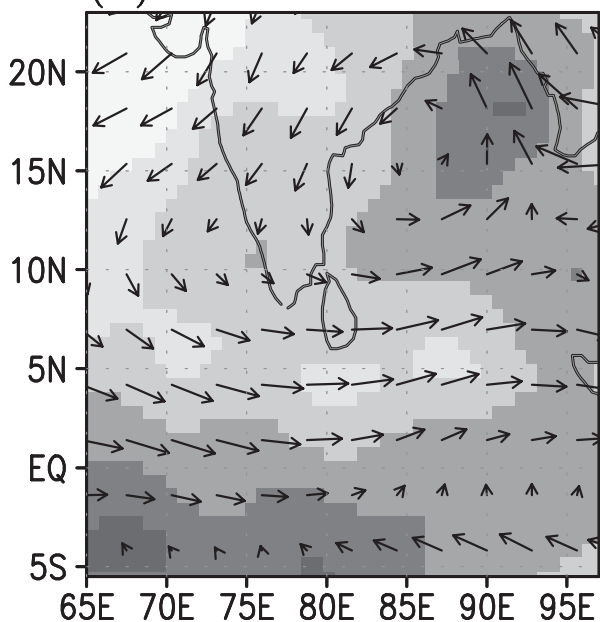

(d) L50

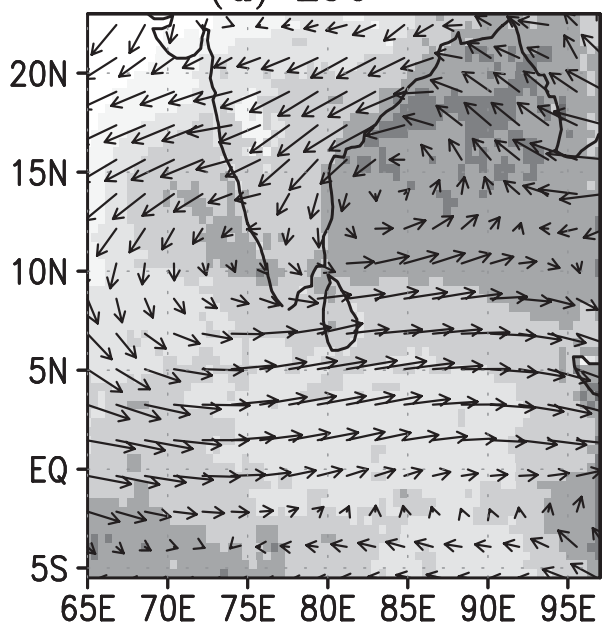

$65 \mathrm{E}$ 70E 75E 80E 85E 90E 95E

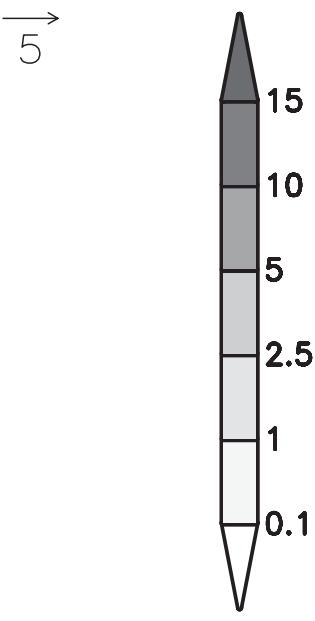

FIG. 4. Seven-member ensemble mean of monthly precipitation $\left(\mathrm{mm} \mathrm{day}^{-1}\right)$ and $850-\mathrm{hPa}$ winds $\left(\mathrm{m} \mathrm{s}^{-1}\right.$ ) in October 2000 for (a) observed TRMM rain and NNR winds at $850 \mathrm{hPa}$, (b) ECHAM4.5 T42, (c) RegCM3 L100, (d) RegCM3 L50, and (e) RegCM3 L25. 
(a) TRMM rain \& NNR winds

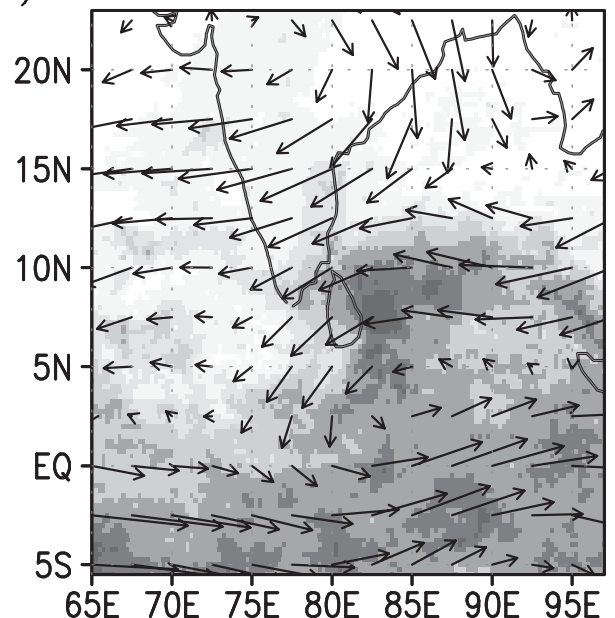

(b) ECHAM4.5 T42

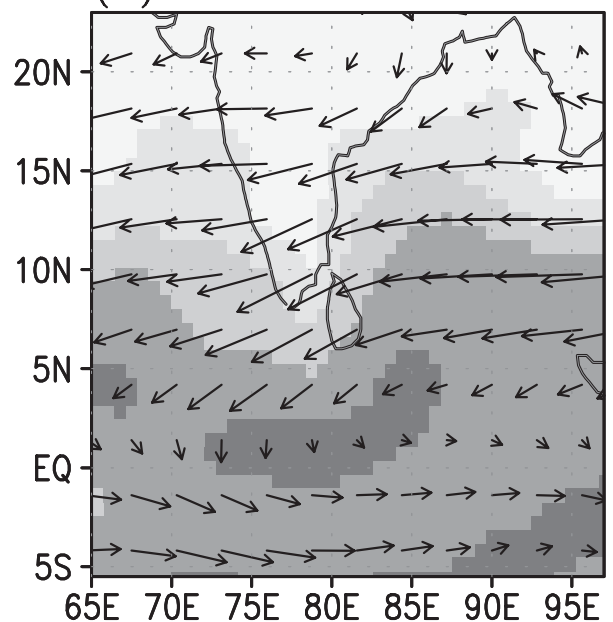

(c) L100

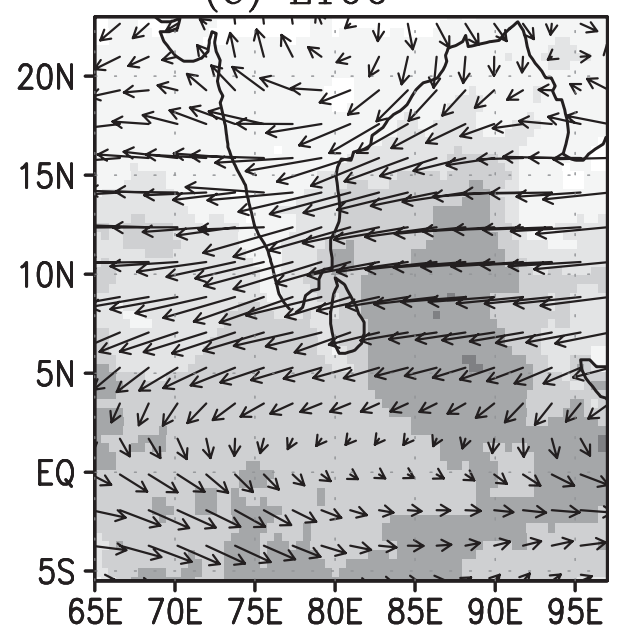

(d) L50

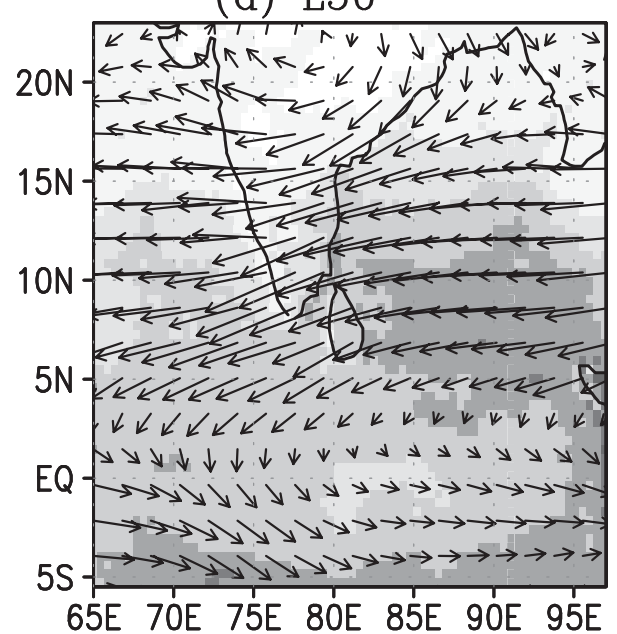
(e) L25
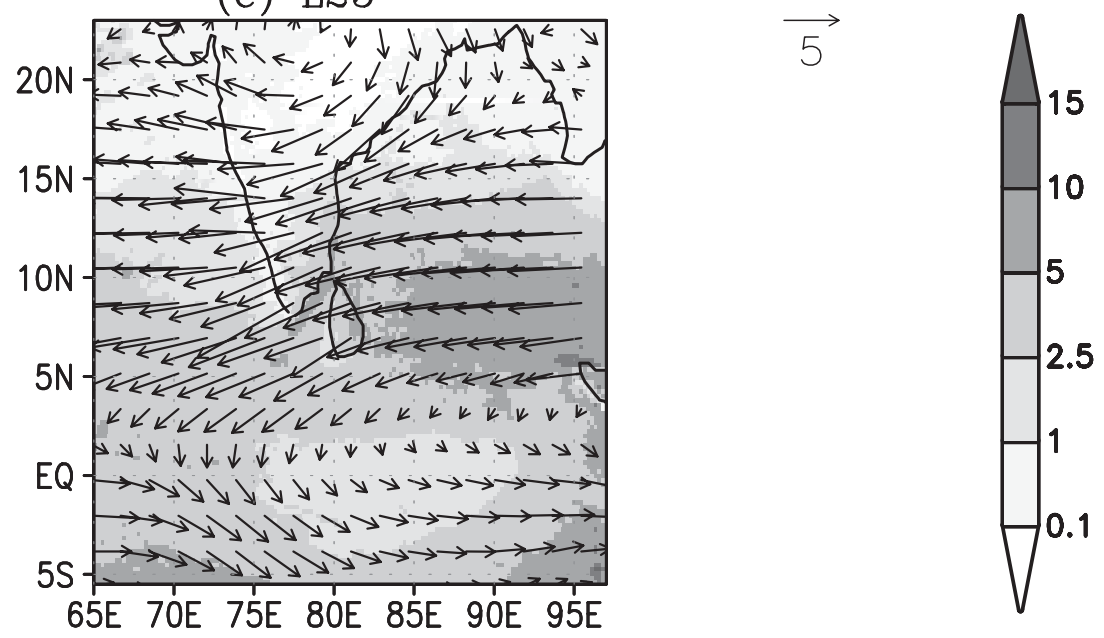

FIG. 5. As in Fig. 4, but for December 2000. 
(a) TRMM rain \& NNR winds

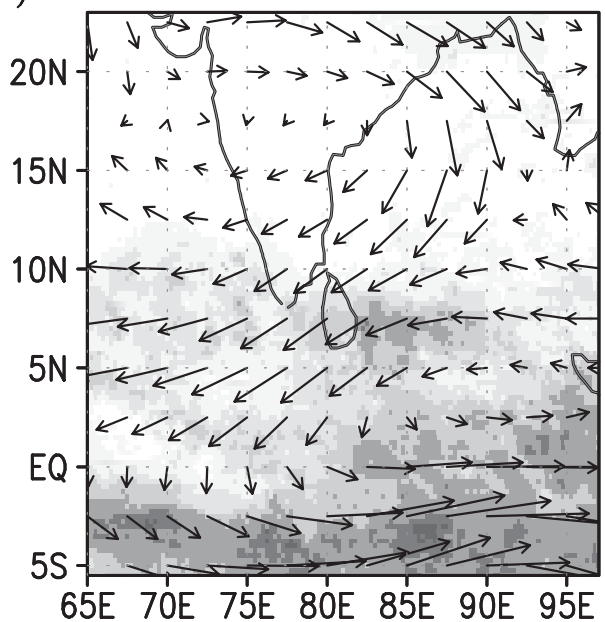

(b) ECHAM4.5 T42

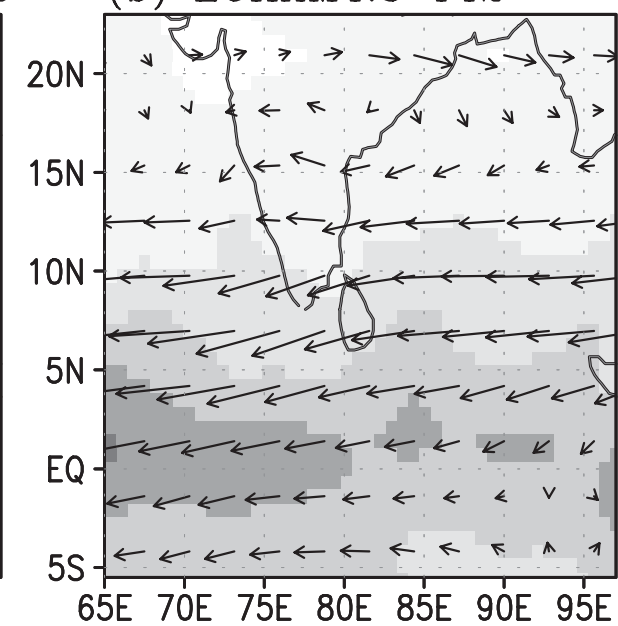

(c) $\mathrm{L} 100$

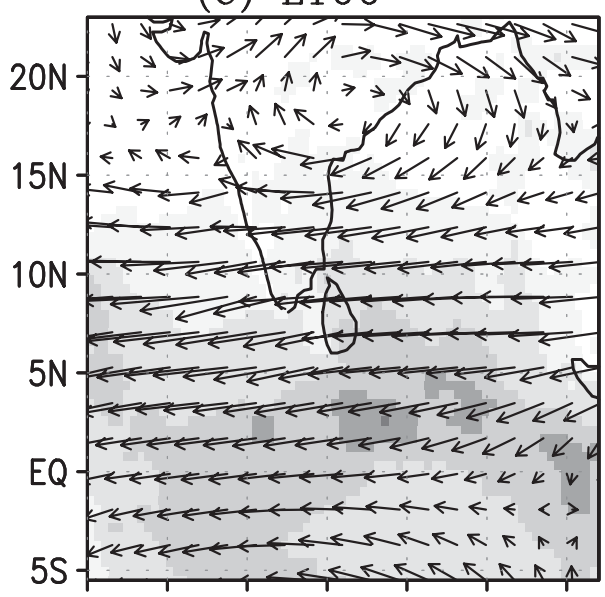

(d) $\mathrm{L} 50$

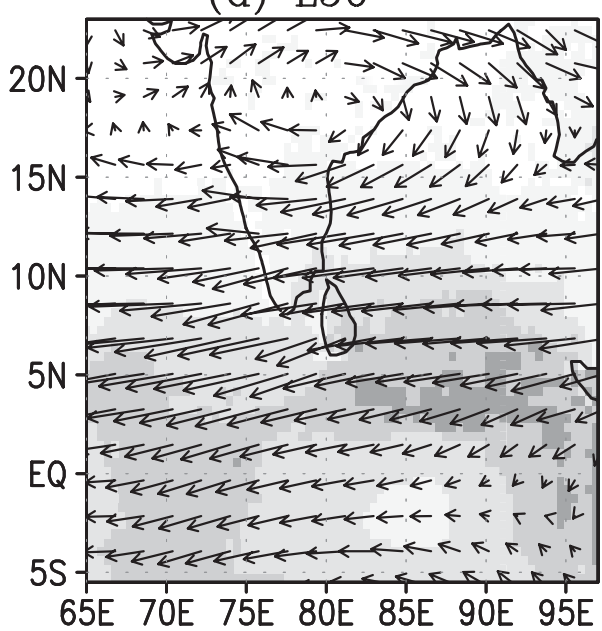

65E 70E 75E 80E 85E 90E 95E

65E 70E 75E 80E 85E 90E 95E

(e) L25
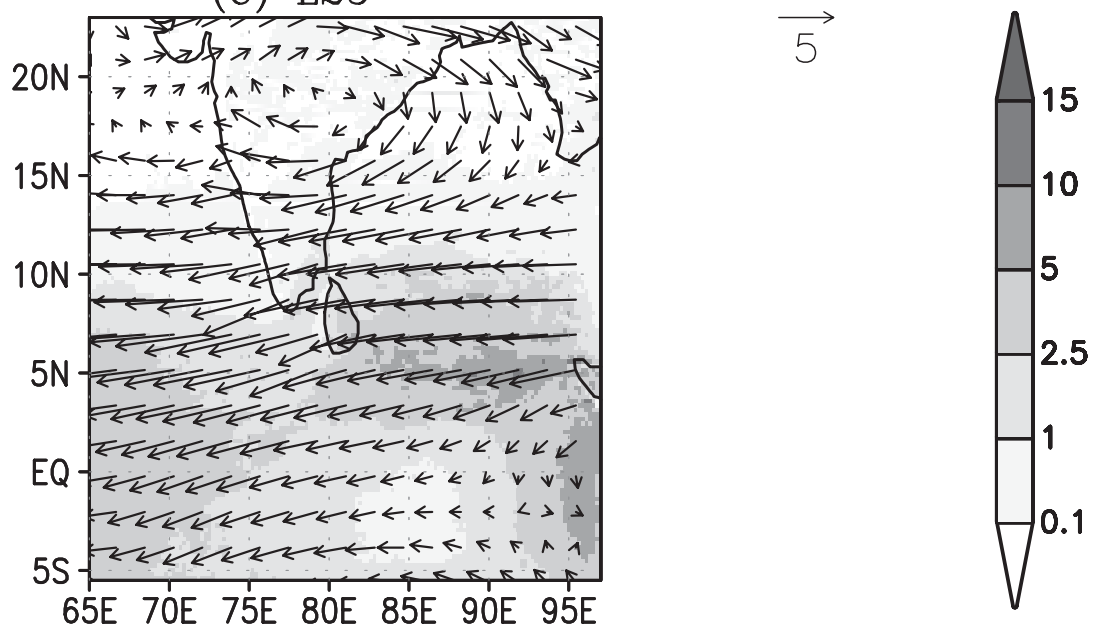

FIG. 6. As in Fig. 4, but for February 2001. 
850-hPa winds over southern India and Sri Lanka are blown up in Figs. 7 and 8 for October and November 2000 , respectively. These two months were chosen to show the results of different large-scale wind regimes. October 2000 is the only month during the simulation period in which the region is dominated by westerlies. The terrain height in Sri Lanka and Tamil Nadu is shown by contours (with interval of $250 \mathrm{~m}$ ) in Figs. $7 \mathrm{c}$ and $8 \mathrm{c}$. Although the precipitation distribution in the TRMM estimates and that based on station observations is similar, there are still small-scale differences (e.g., Figs. 7b,c and $8 \mathrm{~b}, \mathrm{c})$. As the ECHAM GCM is at a coarse resolution, its outputs do not capture the high-resolution features in the observations (Figs. 7a and 8a).

Dramatic differences in precipitation distribution are found in the simulations with different domain sizes. The three large domain simulations (L100, L50, and L25; Figs. 7d-f) show smoother spatial distribution of precipitation over both land and ocean with slightly more precipitation in the windward side of the central mountain range (particularly in the L50 and L25 runs) similar to the observations. The three small domain simulations (S50, S25, and S20; Figs. 7g-i) produce excess precipitation in small areas near the mountain peaks in Sri Lanka and Tamil Nadu, but only little rainfall over the ocean. In reality, heavy precipitation is sometimes also observed over tropical oceans. Thus, it seems that the small domain simulations are overly controlled by the mechanical forcing of the driving field from the ECHAM and contain large biases.

The wind speeds in the ECHAM results (Fig. 7a) are much weaker than those in the NNR reanalysis (Fig. 7b) around Sri Lanka. In the three small-domain simulations, the wind speeds are also very small, similar to those driving ECHAM simulations. In contrast, the large-domain simulations (especially the L50 and L25 runs) have larger wind speeds. The wind directions in these simulations resemble the driving ECHAM simulations rather than the NNR data. This confirms that if the domain of a regional model is too small, it would be overly controlled by the driving field, leaving inadequate freedom for the regional model to generate its internal variability (Giorgi and $\mathrm{Bi}$ 2000).

Because of their different horizontal grids and vertical levels and different types of physics packages, subtle inconsistencies may exist in the lateral buffer zone between the interpolated ECHAM driving fields and the internal dynamics of the RegCM3. These inconsistencies exert the strongest impact on smaller-domain simulations through lateral boundary forcing, especially by the upper-level ventilation or "flushing" effect (McGregor 1997; Laprise et al. 2008). In our small-domain simulations, the rainfall is underestimated in the buffer zone, so that exessive moisture is left to enhance rainfall near the mountain tops (Figs. 7g-i and 8g-i). Laprise (2008) and Leduc and Laprise (2009) also pointed out that simulations with overly small regional model domains may have a spatial spinup problem if there is insufficient space to generate fine scales.

The impact of grid spacing on the orographic precipitation is also examined. In October (Fig. 7), the dominant winds are westerlies, and the TRMM and Sri Lanka station observation show that maximum precipitation is on the southwestern side of the central mountain range resulting from moist condensation of the uplifting air over the windward side. However, this feature is not reproduced in the L100 simulations. This shortcoming is due to insufficient mountain heights in the $100-\mathrm{km}$ grid model. The L50 simulations show slightly greater precipitation over the western slopes than the eastern slopes. The L25 runs produce maximum precipitation on the correct location over the southwestern slope as in the station data, but the magnitude is still less than that of the station observation.

In November, when the northeasterlies prevail, the TRMM and station observations show heavier precipitation on the eastern side of Sri Lanka (Figs. 8b,c). The ECHAM results correctly show larger amounts of precipitation in the eastern part of Sri Lanka, even with the coarse resolution of $2.8^{\circ}$, indicating good performance of the GCM for this month (Fig. 8a). The large-domain simulations L100 and L50 show a decreasing gradient of precipitation from east to west. The precipitation is shifted in the direction of the wind in both simulations relative to the observations (Figs. 8d,e). The L25 runs give relatively large precipitation on the eastern slopes similar to the observations (Fig. 8f). The three small-domain simulations, however, produced heavy precipitation on the wrong side (Figs. $8 \mathrm{~g}-\mathrm{i}$ ). Note that the intensity of the simulated maximum precipitation is still underestimated and the finescale structure of precipitation in the station observation is not fully reproduced even with $25-\mathrm{km}$ grid (L25). Proper simulation of precipitation processes probably needs cloud-scale models (Tao et al. 2003). Nonetheless, these findings show that higher-resolution alone cannot compensate for an overly small domain size in regional models.

\section{Uncertainties in the ensemble simulations in the global and regional models}

\section{a. Definition of ensemble mean, ensemble spread, and relative ensemble spread}

To account for uncertainties in the global climate model simulation and forecast, multiple ensemble members were run using the same model but with slightly 
(a) ECHAM4.5 T42

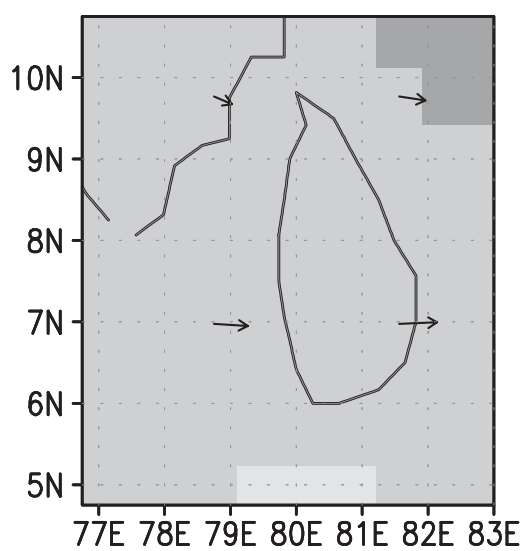

(d) L100

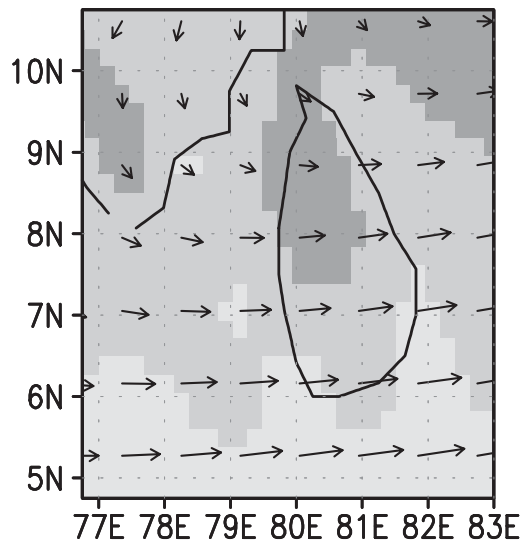

(g) $\mathrm{S} 50$

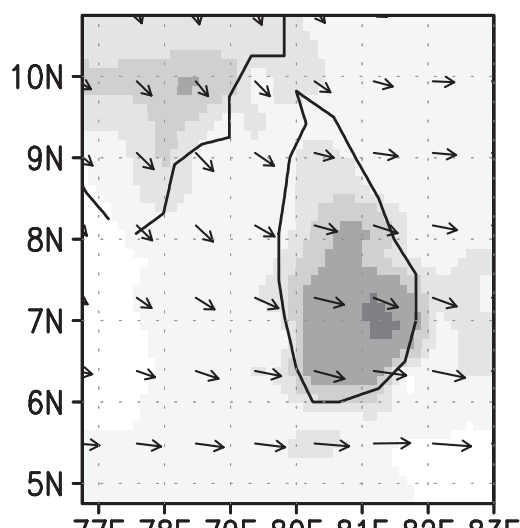

77E 78E 79E 80E 81E 82E 83E (b) TRMM rain \& NNR winds

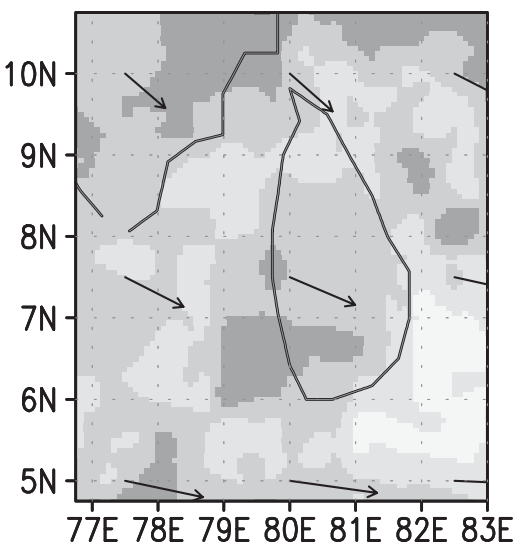

(e) L50

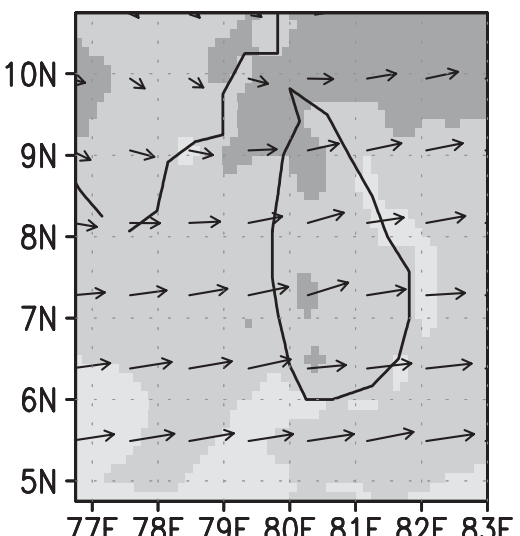

(h) $\mathrm{S} 25$

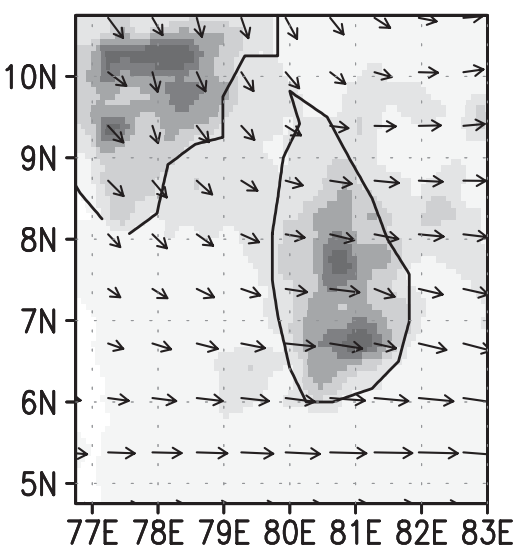

(c) Station rain \& terrain

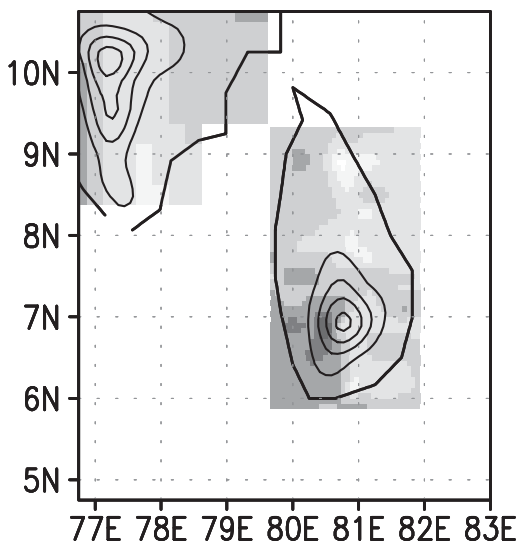

(f) L25

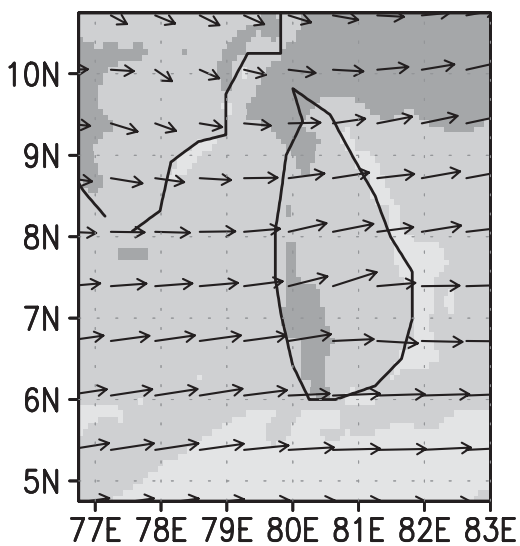

(i) $\mathrm{S} 20$

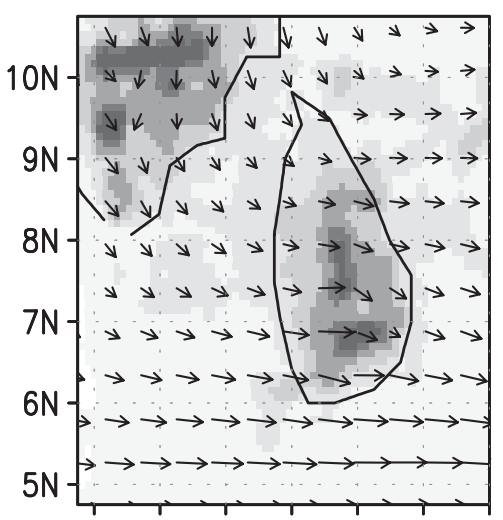

77E 78E 79E 80E 81E 82E 83E

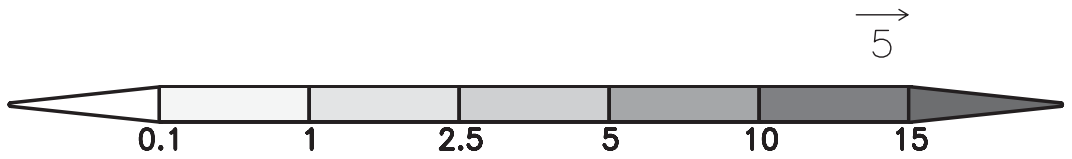

FIG. 7. Seven-member ensemble mean of monthly precipitation $\left(\mathrm{mm} \mathrm{day}^{-1}\right)$ and $850-\mathrm{hPa}$ winds ( $\mathrm{m} \mathrm{s}^{-1}$ ), October 2000: (a) ECHAM4.5 T42, (b) observed TRMM precipitation and NNR winds, (c) terrain heights (contours) and Indian and Sri Lankan station observation of rainfall, and ensemble mean of RegCM3 simulations of (d) L100, (e) L50, (f) L25, (g) S50, (h) S25, and (i) S20. 
(a) ECHAM4.5 T42

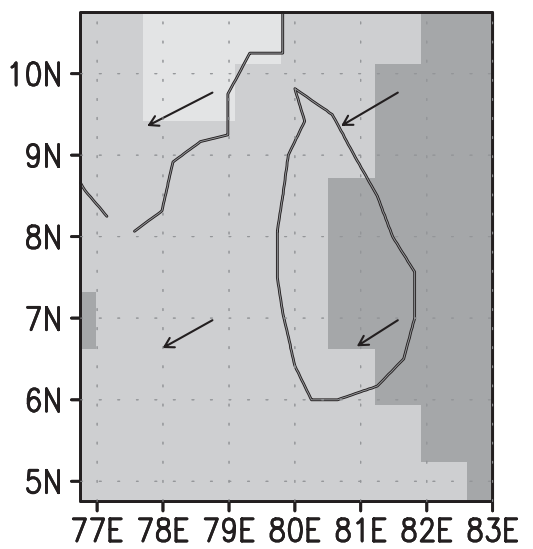

(d) L100

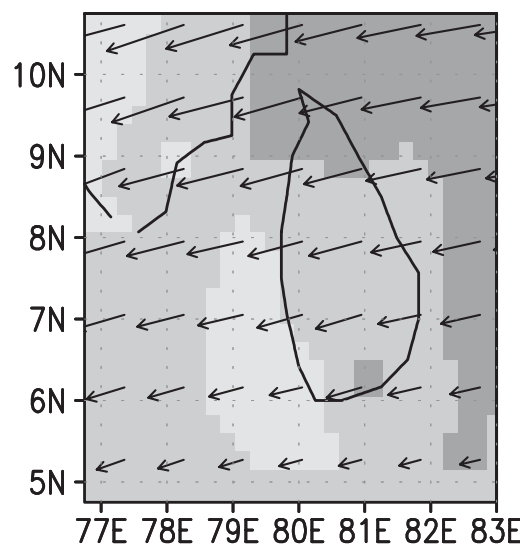

(g) $\mathrm{S} 50$

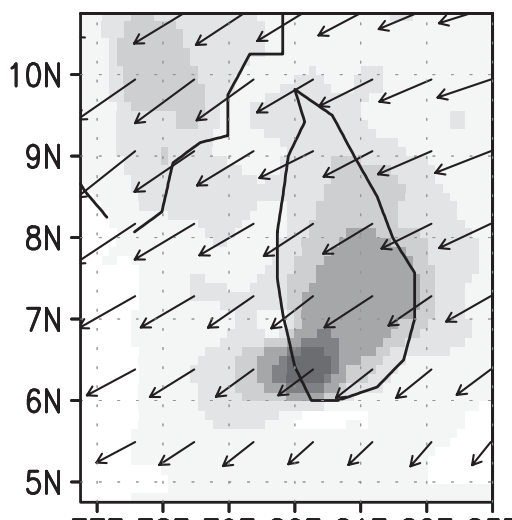

77E 78E 79E 80E 81E 82E 83E (b) TRMM rain \& NNR winds

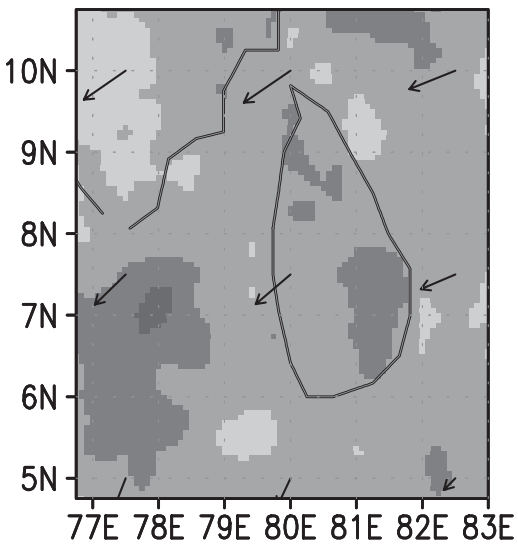

(e) L50

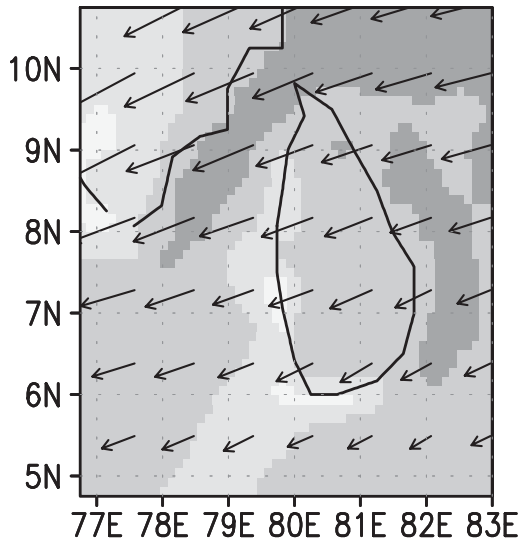

(h) S25

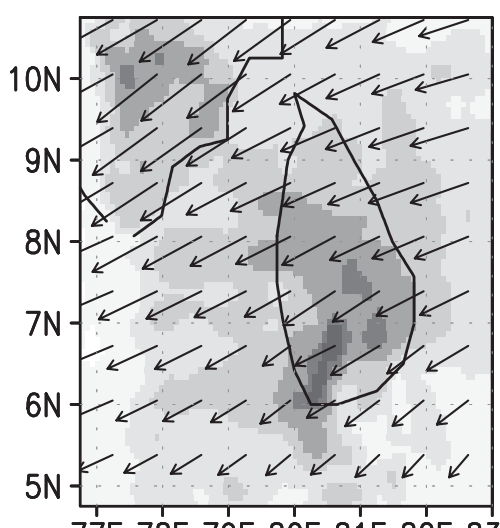

77E 78E 79E 80E 81E 82E 83E (c) Station rain \& terrain

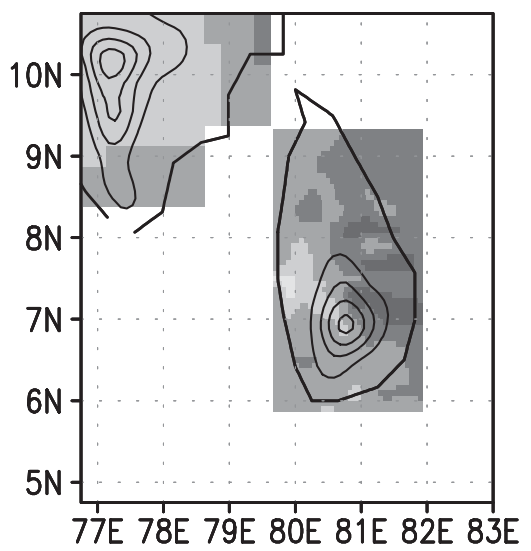

(f) L25

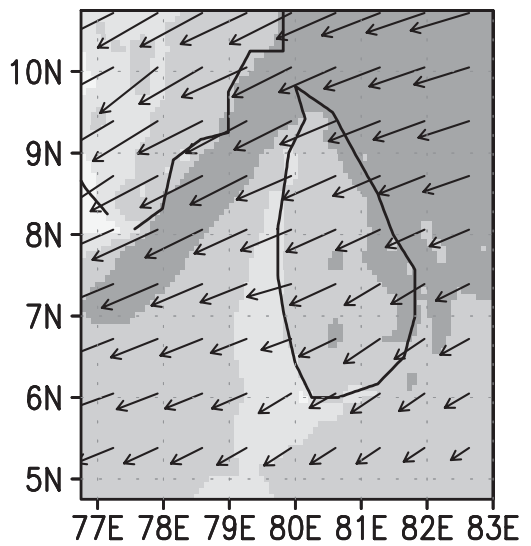

(i) $\mathrm{S} 20$

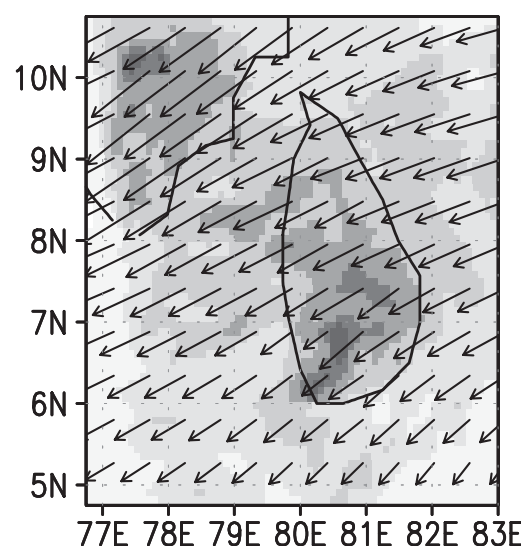

5

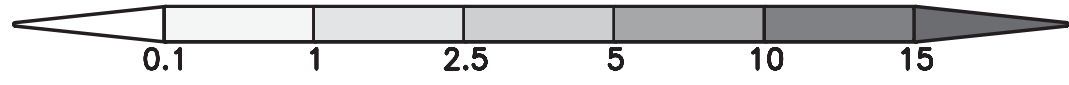

FIG. 8. As in Fig. 7, but for November 2000. 
different initial conditions (taken from different days). Then each realization of the global model run is used to drive the regional model. To quantify the uncertainties, the following measures are defined based on the time series of monthly mean values from different ensemble members. The ensemble spread $S$ is the square root of variance between ensemble members:

$$
S^{2}=\frac{1}{M} \sum_{m=1}^{M}\left[X_{m}(t)-\overline{X(t)}\right]^{2},
$$

where $M$ is the total number of ensemble members $(M=7)$ and $\overline{X(t)}$ is the ensemble mean:

$$
\overline{X(t)}=\frac{1}{M} \sum_{m=1}^{M} X_{m}(t) .
$$

A relative (or normalized) ensemble spread is defined by the ratio of the ensemble spread to the ensemble mean: $S / \overline{X(t)}$.

The 6-month-averaged ensemble mean, ensemble spread, and relative ensemble spread (shown as percentage) over the whole island of Sri Lanka in the ECHAM4.5 and six RegCM3 simulations are given in Table 1. In terms of time averages, the ensemble mean in the RegCM3 simulations are larger than that in the GCM, indicating reduction of systematic biases as compared to the observations (also see Fig. 10). The magnitude of the ensemble spread in the RegCM3 large-domain simulations is similar to that in the GCM. Therefore, the relative ensemble spread is significantly smaller than that in the GCM, especially in the L25 simulation. The three small-domain simulations have larger values than the GCM in both ensemble mean and ensemble spread, so the relative ensemble spread is only slightly smaller than that in the GCM. In the following, we will examine the variability of the ensemble means and spreads spatially and temporally.

\section{b. Ensemble spread in the global model}

Figure 9 shows the seven-member ensemble simulations of ECHAM4.5 over the south Asian and Indian Ocean region in November 2000. Figure 9a is the TRMM precipitation and NNR reanalysis winds over $850 \mathrm{hPa}$, used as an observational reference for comparison. Figures $9 \mathrm{~b}-\mathrm{h}$ are results of each of the seven ensemble members of ECHAM4.5, respectively. Figure $9 i$ is the ensemble mean obtained by averaging the seven ensemble members.

Comparison of the observation Fig. 9a and the ensemble mean Fig. 9i indicates that the gross features of the large-scale intertropical convergence zone (ITCZ) with rainfall over the tropical Indian Ocean are simulated well by the ECHAM4.5. Similarly, the northeasterly monsoonal winds over Sri Lanka are simulated quite well by the ensemble mean. During November, low-level westerly winds prevail over the eastern Indian Ocean, converging to a large-scale precipitation center over the western Maritime Continent around the islands of Sumatra, Borneo, and Java.

Note that the speed of the equatorial westerlies over the central and eastern Indian Ocean is underestimated in the ECHAM4.5 ensemble mean. This is probably caused by the underestimation of rainfall over the western Maritime Continent region near Sumatra (Fig. 9i) as compared to the observation (Fig. 9a). Qian (2008) found that the bias of rainfall over the Maritime Continent in the coarse-resolution ECHAM4.5 is due to the underrepresentation of the complex topography of islands, seas, and mountains and the associated landsea breezes and mountain-valley winds. The underestimated rainfall over the Maritime Continent in the GCM acts to weaken the low-level convergence and thus reduce low-level westerlies over the tropical Indian Ocean.

In spite of some similarities in the ensemble mean and observation, there exist remarkable differences between the ensemble members, as shown in Figs. 9b-h. For example, some members $(1,5$, and 6) simulate more precipitation over the Bay of Bengal while others (4 and 7) simulate less precipitation there. The zonal distribution of rainfall in the tropical Indian Ocean is also very different. Maximum rainfall is located over the eastern Indian Ocean in ensemble numbers 2 and 3, over the central Indian Ocean in ensemble numbers 5 and 7 , over both the central and eastern Indian Ocean in number 6, and over the western Indian Ocean in ensemble number 4. Because of the weak Coriolis effect in the low latitudes, low-level winds tend to converge directly to areas of high precipitation and rising air. Therefore, the easterly winds in the tropical Indian Ocean in ensemble number 4 are opposite in direction to the westerlies in other ensemble members. Over Sri Lanka, however, all ensemble members reproduce northeasterly flow at the $850 \mathrm{hPa}$ despite the significant differences in precipitation (Figs. 9b-h).

Figure 9 shows that the ensemble spread in the global model simulation is large. Unlike regional models that are controlled by certain lateral boundary conditions, global models are not subject to such horizontal constraints. Hence, a horizontally autonomous global model has a large degree of freedom to generate rather different results among its ensemble realizations resulted from the nonlinear and chaotic nature of the atmospheric 
(a) TRMM rain, NNR winds

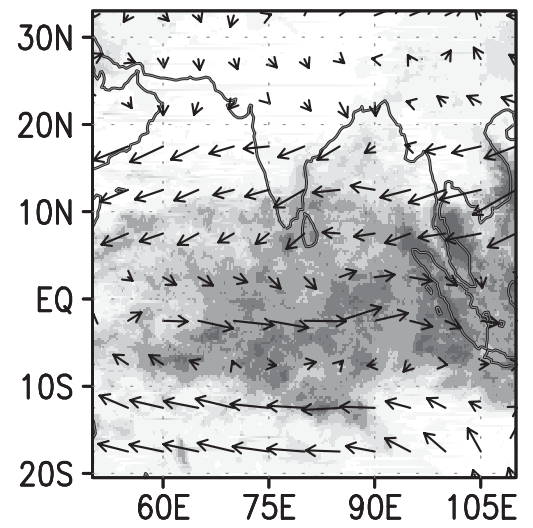

(d) ECHAM4.5 \#3

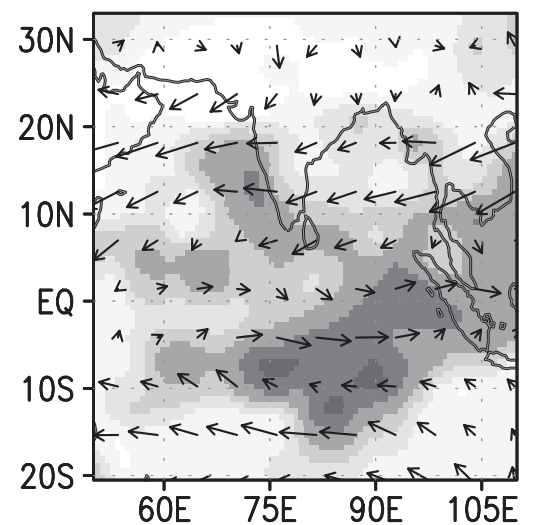

(g) ECHAM4.5 \#6

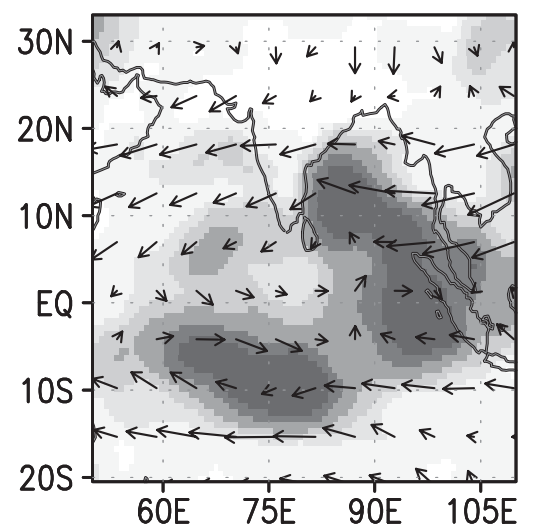

(b) ECHAM4.5 \#1

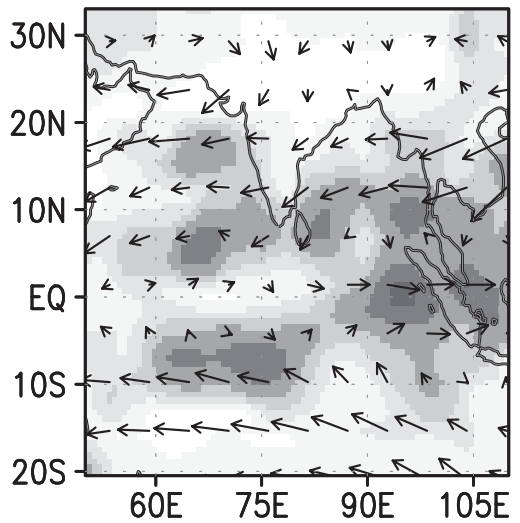

(e) ECHAM 4.5 \#4

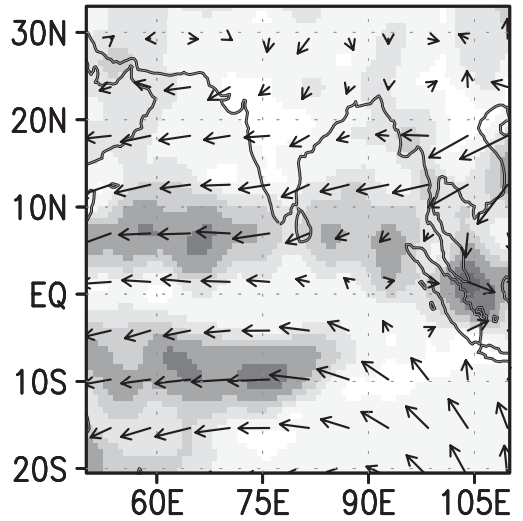

(h) ECHAM4.5 \#7

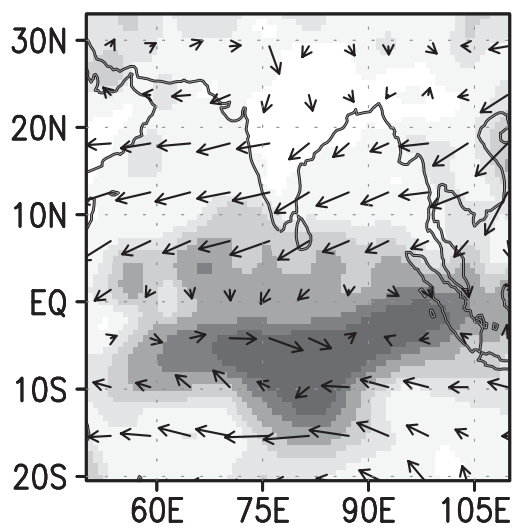

(c) ECHAM4.5 \#2

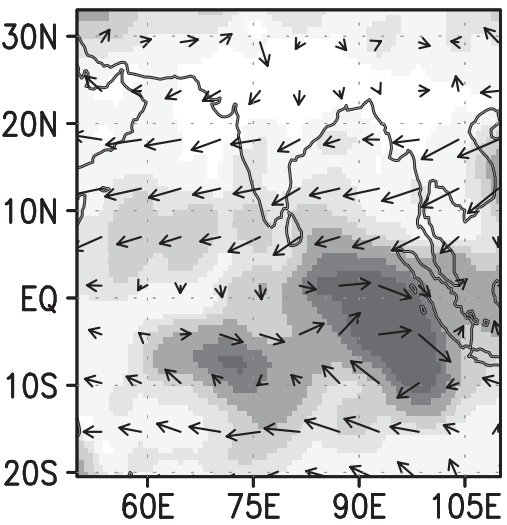

(f) ECHAM4.5 \#5

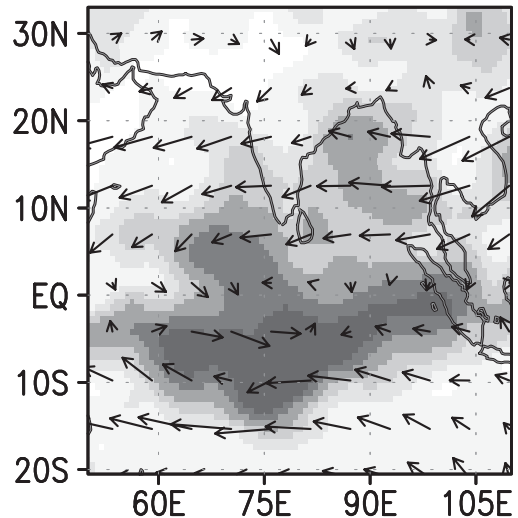

(i) ECHAM4.5 ensemble mean

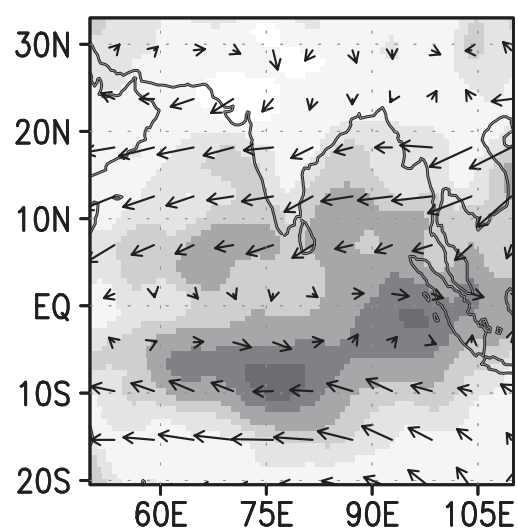

10

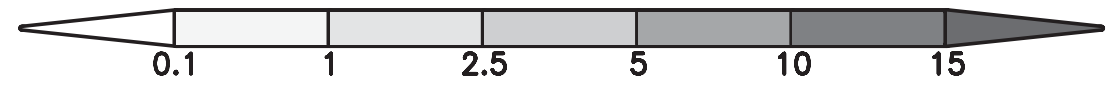

FIG. 9. Monthly precipitation ( $\mathrm{mm} \mathrm{day}^{-1}$ ) and 850-hPa winds $\left(\mathrm{m} \mathrm{s}^{-1}\right)$ in November 2000: (a) observed TRMM rainfall and NNR reanalysis winds, (b)-(h) ECHAM4.5 ensemble members 1-7, respectively; and (i) the seven-member ensemble mean. 
dynamics (Lorenz 1963). The large differences among the ensemble members in south Asia are quite evident in Fig. 9.

Nevertheless, in terms of 850 -hPa winds immediately around Sri Lanka, all members of the ECHAM4.5 successfully simulated the northeasterly monsoon. Therefore, even though rainfall over Sri Lanka and the surrounding region may be poorly simulated in the ECHAM4.5, it is possible to improve the rainfall simulation by the RegCM3 downscaled simulation, considering that the wind-terrain interaction may correct the local rainfall distribution over the eastern versus that on the western mountain slopes.

\section{c. Comparison of ensemble means and spreads in the global and regional models}

To characterize the evolution of ensemble spread between ensemble members, the monthly precipitation time series of the GCM and the regional model simulations are compared with that of the observational time series. Figure 10a shows the time series of the averaged rainfall from station observations and the ECHAM4.5 simulated monthly precipitation in the 2000-01 winter season over the Sri Lankan area $\left(5.8^{\circ}-9.4^{\circ} \mathrm{N}, 79.6^{\circ}-\right.$ $82.0^{\circ} \mathrm{E}$ ). The magnitude of ECHAM precipitation is much smaller than the observations, particularly from November to February, indicating that the GCM significantly underestimates the precipitation over Sri Lanka. The observations show that October 2000 is a relatively dry month and that November 2000 is the rainiest month during this period. These ECHAM simulations, however, produce large amount of precipitation in October with declines in November and December followed by a slight increase from January to February 2001. Figure 1a shows that the island of Sri Lanka is not captured in the ECHAM4.5 topography. Therefore, the ECHAM cannot simulate the topographic rainfall associated with the wind-terrain interaction (Chang et al. 2005; Xie et al. 2006) and the sea-breeze and valley-breeze convergences (Qian 2008). That is probably the reason why ECHAM4.5 significantly underestimates rainfall over Sri Lanka.

Figure 10b shows the time series of monthly mean precipitation by the seven-member ensemble simulations of the RegCM3 L25 for Sri Lanka. Compared to the ECHAM precipitation in Fig. 10a, the magnitudes of precipitation in the RegCM3 runs are larger (Fig. 10b, also see Table 1 for the seasonal averaged values); that is, the regional model downscaling helps in reducing the systematic biases. The L25 run produces more precipitation in November than in October in eastern Sri Lanka (Figs. $7 f$ and 8f) and for the whole Sri Lanka (Fig. 10b) in keeping with observations. The lower atmosphere is dominated by northeasterlies in November, leading to heavy precipitation over the eastern slope (Fig. 8f). Figure 10a shows that the monthly rainfall trend from October to November is not captured by most of the ensemble members of the ECHAM simulation ( 6 out of 7 members are incorrect, except for ensemble number 6 in which heavy rainfall is found over Sri Lanka in November as shown in Fig. 9g). The station observation (Fig. 3) shows that heavy rainfall in November falls over the eastern slopes of Sri Lanka by the uplifting of northeasterly monsoonal winds at the windward side of the central mountain range. But the coarse-resolution ECHAM4.5 cannot reproduce this windward side orographic rainfall over Sri Lanka in November. In contrast, 6 out of 7 members of the RegCM3 simulation (except for number 3 ) correct the trend such that rainfall increases from the October to November (Fig. 10b).

Figure 11 shows all ensemble means of model simulations over four regions (Tamil Nadu, the western and eastern slopes, and the whole of Sri Lanka) for the ECHAM, and the RegCM3 runs of L100, L50, L25 (marked by squares); and S50, S25, and S20 (marked by circles). The TRMM and station observations are also plotted as references. The values of the ensemble mean of the seven-member ECHAM simulations are very small compared to the observations, and they decrease from October to January. Note that the ECHAM-simulated ensemble means over Tamil Nadu (Fig. 11a) and Sri Lanka (Fig. 11d) are exactly the same because of the coarse resolution of the GCM. The RegCM3 runs enhance the magnitude of precipitation in relation to that of the GCM. The magnitudes and temporal variation of the ensemble means of the three large-domain simulations are similar to each other. The magnitudes of the ensemble means of the three small-domain simulations are generally larger than that of the large-domain simulations. This implies that the regional model is more sensitive to domain size than to grid spacing.

The month-to-month trend of the RegCM3 simulations generally follows that of the ECHAM runs, except for February and March 2001 (Fig. 11). There are some differences between the ECHAM and RegCM3 runs similar to that shown in Fig. 10. The increase of precipitation from October to November in the three smalldomain model simulations corresponds better to the observations (Figs. 11b-d); therefore, they seem to have corrected the erroneous trend in the ECHAM simulations. However, this correction might be due to the wrong reasons considering the overreaction of the model atmosphere to the lateral boundary forcing and topographic effect in the small domain simulations as shown in the previous section. Nevertheless, the results imply that the 

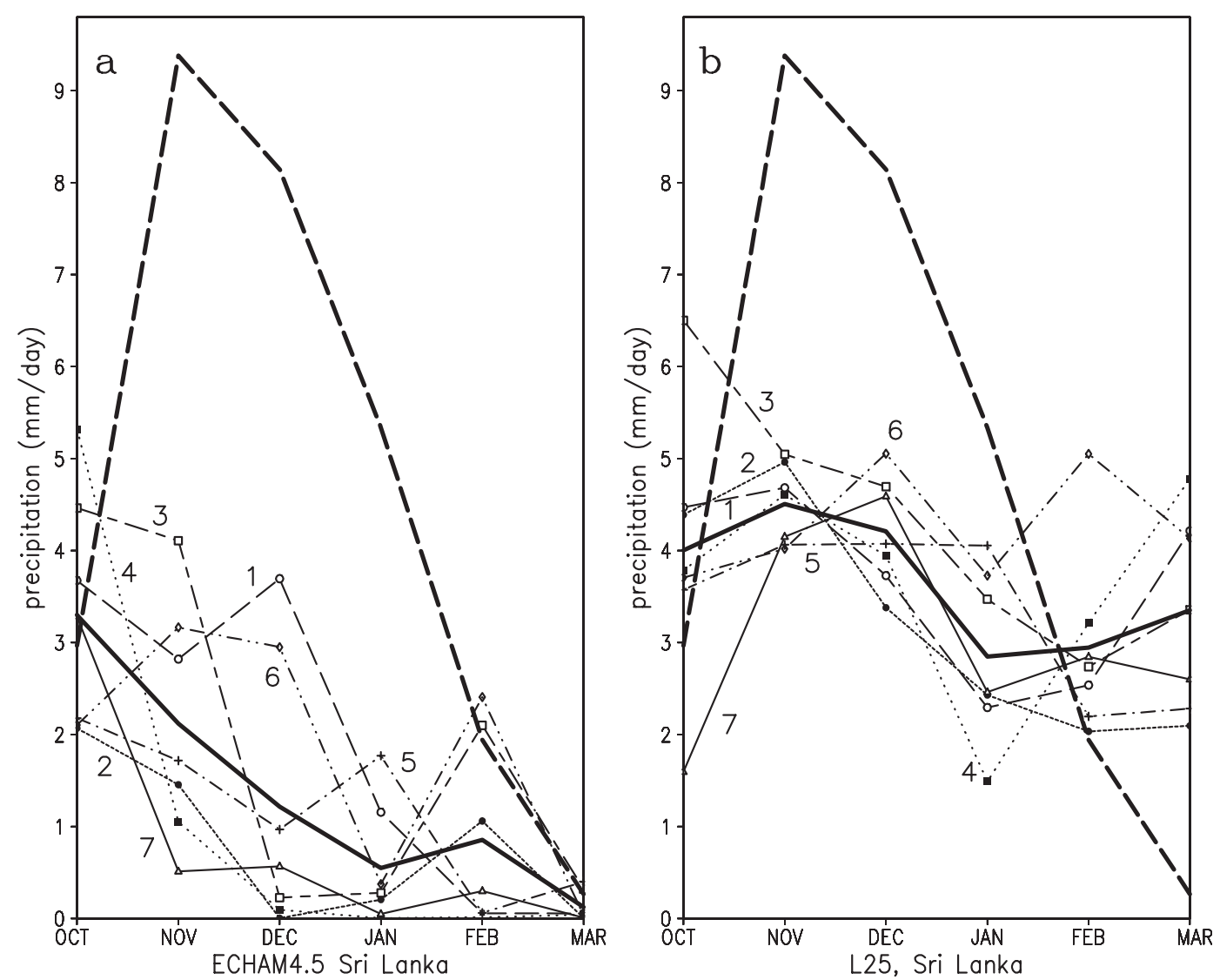

FIG. 10. Time series of monthly precipitation $\left(\mathrm{mm} \mathrm{day}^{-1}\right)$ from October 2000 to March 2001, for station observation (thick dash), and seven-member ensemble realizations (thin solid), and ensemble means (thick solid) over the whole Sri Lanka in (a) the ECHAM4.5 simulations and (b) the RegCM3 large-domain 25 km-grid simulations (L25).

high resolution in the small-domain runs helped correct the temporal precipitation trend. The large-domain simulations of L25 also correctly reproduced the transition of precipitation from October to November in the eastern slopes and the whole island (Figs. 11c,d). This result seems more robust in the light of the good performance of L25 in simulating the spatial distribution of precipitation described earlier. Therefore, it appears that both high resolution and large domain size of regional models are critical for climate downscaling in this region.

To assess uncertainties in the ensemble simulation, we examine in Fig. 12 the month-to-month evolution of the relative ensemble spread, the ratio of the ensemble spread to the ensemble mean as defined by (2) and (3), for the four regions as in Fig. 11. Fox-Rabinovitz et al. (2005) showed similar time series but used the ensemble spread as the measure of uncertainty for a GCM ensemble simulation. Considering the ensemble means are quite different among our experiments (Table 1), we choose to show the relative ensemble spread instead. The ECHAMsimulated relative ensemble spread is small $(13 \%)$ in the October, but it increases to above 30\% after December.
The ECHAM has the largest relative ensemble spread almost all the time in comparison to that of the RegCM3 ensemble simulations (Figs. 12a,d).

The three small-domain simulations (S50, S25, and S20) have large relative spreads, which share similar month-to-month evolution to that of the ECHAM (and the spread of S50 is slightly larger than that of S25 and S20). This indicates that small-domain models of RegCM3 are strongly controlled by the ECHAM forcing through the lateral boundary forcing; thus they inherit the large relative spread in the ECHAM ensembles. It is also worth noting that the ensemble spread is larger over smaller averaged areas (i.e., smaller in Figs. 12b,c than in Fig. 12d) in the small-domain simulations that produce heavy rainfall at the wrong side of the central mountain range of the island. Even though the mean biases are reduced in the small-domain runs, the ensemble uncertainties are still undesirably large.

In comparison, the three large-domain simulations (L100, L50, and L25) have smaller relative spreads than the small-domain simulations (except for the L100 occasionally in some months). The L100 run has a large 

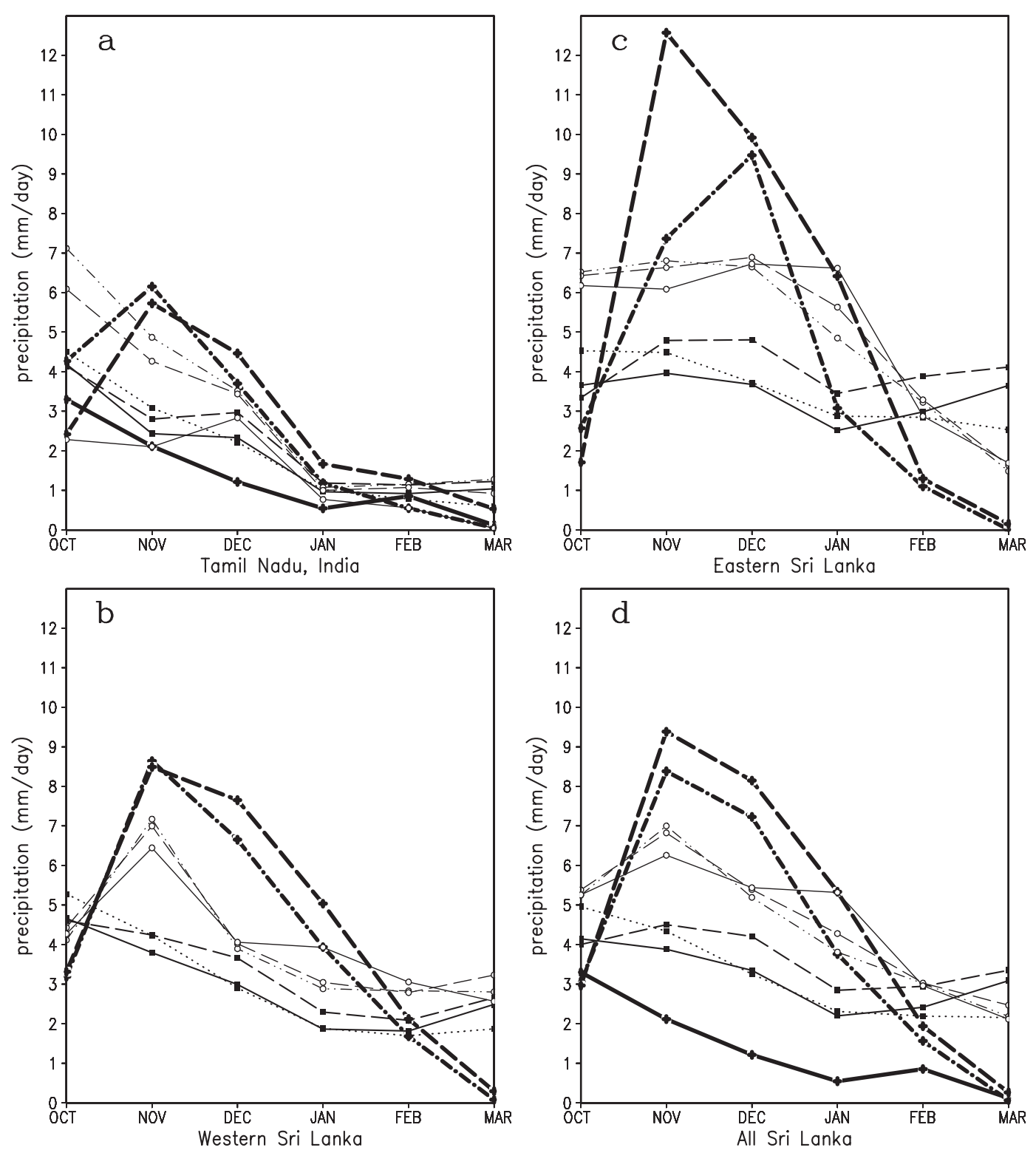

FIG. 11. Time series of monthly precipitation $\left(\mathrm{mm} \mathrm{day}^{-1}\right.$ ) from October 2000 to March 2001, for TRMM (thick black cross-dot-dash), station observation (thick black cross-dash), ensemble means for ECHAM4.5 (thick black crosssolid), RegCM3 L100 (square-dot), L50 (square-solid), L25 (square-dash), S50 (circle-solid), S25 (circle-dash), and S20 (circle-dot-dot-dash) over (a) Tamil Nadu of India, and (b) western, (c) eastern, and (d) whole Sri Lanka.

relative spread, indicating that the insufficient representation of the land and mountain topography limits the capacity of the regional model to capture regionalscale rainfall. The relative ensemble spreads in the RegCM3 simulations are minimum in the second month (in November) of the 6-month-long simulations (OctoberMarch). In the initial month (October), RegCM3 inherits the large ensemble spread from the GCM ensemble. Then the RegCM3 internal dynamics, interacting with local surface forcing, generates similar results among the ensemble members, and narrows down the ensemble spread. But with the further increase of time (December and after), the ensemble spread increases. Unlike the ECHAM and small-domain runs in which the relative spreads increase sharply with time after November, the relative spreads in the L50 and L25 do not increase very much with time, indicating improved rainfall simulation in the reduction of both bias and uncertainty over Sri Lanka in the large-domain finegrid runs. 

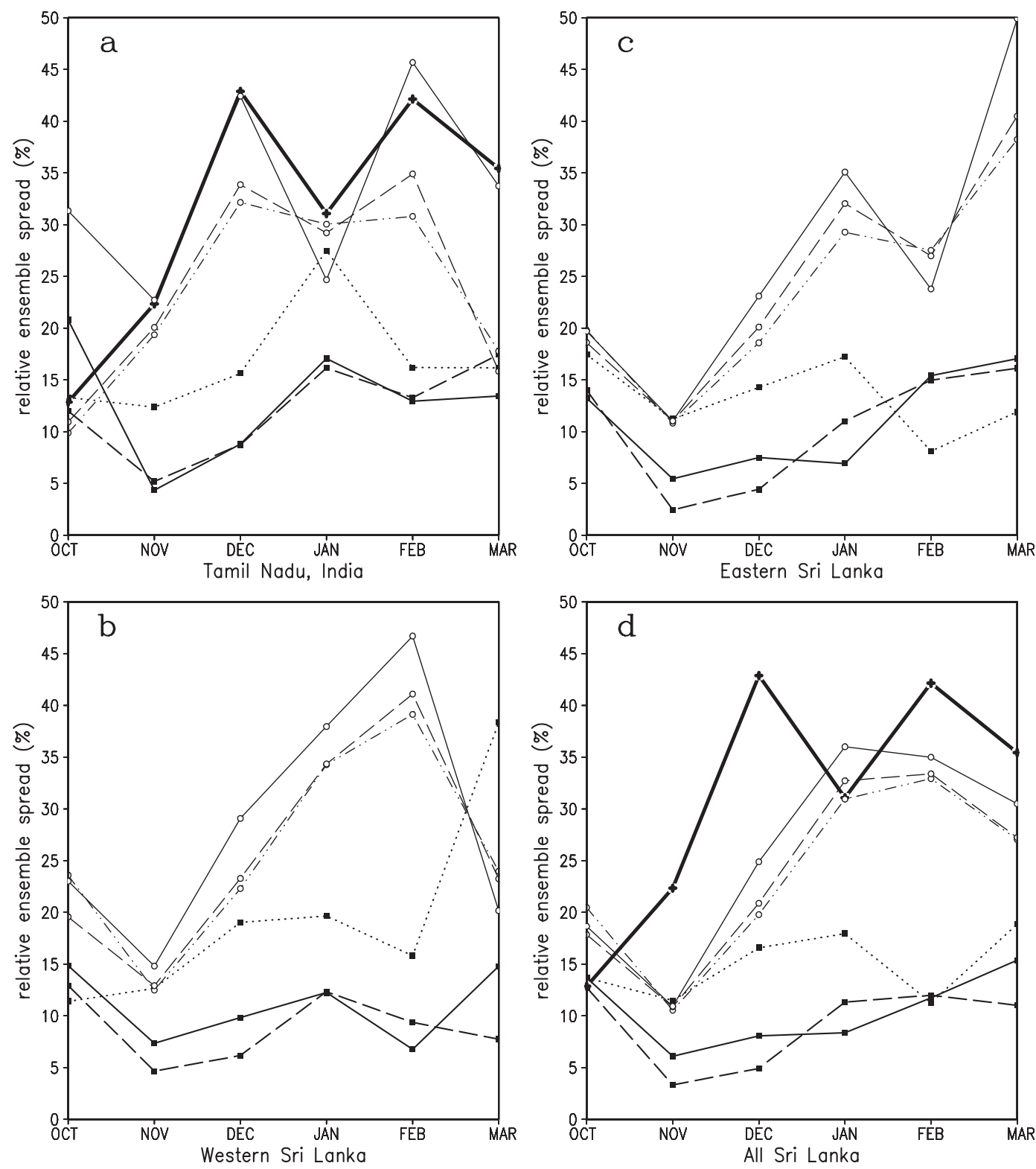

FIG. 12. Time series of relative ensemble spread (percentage) from October 2000 to March 2001, for ECHAM4.5 (thick cross-solid); and the three large-domain RegCM3 simulations: L100 (square-dot), L50 (square-solid), L25 (square-dash); and the three small-domain simulations: S50 (circle-solid), S25 (circle-dash), and S20 (circle-dotdot-dash) over (a) Tamil Nadu of India, and (b) western, (c) eastern, and (d) whole Sri Lanka.

\section{Conclusions and discussion}

By using a regional climate model RegCM3, the GCM ECHAM4.5 ensemble simulations have been downscaled over Sri Lanka and surrounding areas. Two groups of RegCM3 simulations with different domain size have been conducted to evaluate the performance of the dynamical downscaling. The large-domain group produced reasonable distribution of precipitation over both land and ocean regions. However, the small-domain group produced too much rainfall over the mountainous region and too little rainfall near the lateral boundary. When a regional model domain is too small, inconsistencies (between global model forcing and regional model dynamics and physics) in the lateral buffer zone are propagated to the interior of the domain and exert too strong a control over the regional model, thus making it unable to generate physically realistic results associated with the local surface forcing. From the multimember ensemble modeling perspective, another negative effect of small-domain models is 
that they inherit too much ensemble spread (thus uncertainty) from the driving GCM ensemble, which is not pertinent to the local forcing.

The effect of grid spacing on the orographic precipitation was also examined. The results indicate that a grid size smaller than $50 \mathrm{~km}$ is needed to differentiate the precipitation over the eastern and western slopes of the Sri Lankan central mountain range, which is associated with the low-level monsoonal wind directions. Therefore, both sufficiently large model domain and fine-grid resolution are needed for generating orographic rainfall skillfully.

We found added value from regional climate downscaling in simulation of local precipitation distribution and its temporal evolution by comparing the global and regional model results. The underestimation of precipitation in the ECHAM GCM has been mitigated by the RegCM3 downscaling, and the temporal trend of monthly precipitation has been corrected to some extent in the high-resolution (20-25-km grid) runs by the RegCM3 because of the ability of the regional model to simulate orographic rainfall processes.

The uncertainty in ensemble climate downscaling, as measured by the ensemble spread (or the variance among the ensemble members) and relative ensemble spread, is analyzed to examine its sensitivity to model domain size and grid spacing. The ensemble spread decreases drastically with the increase of regional model domain size (i.e., smaller uncertainties are obtained by using larger domain sizes). In contrast, the ensemble spread only moderately decreases with the reduction of grid size (i.e., smaller uncertainties at finer grid spacing). Therefore, for the purpose of reducing ensemble uncertainty in the GCM-driving downscaling, a larger regional model domain size seems to be more effective than a finer grid spacing. However, as we have found in this paper, a fine-grid spacing is needed to correctly simulate the orographic rainfall over Sri Lanka. Moreover, a fine-grid spacing is also beneficial in reducing ensemble uncertainties. In conclusion, a large-domain RegCM3 with a reasonably fine grid is needed to enhance the skill of the ensemble regional climate downscaling over south Asia.

In numerical models, precipitation is usually more difficult to simulate than the wind circulation field because of the complexity of moist precipitation processes. We indeed saw a widely dispersed ensemble spread in precipitation in the ECHAM ensemble members (Fig. 9), but a relatively good agreement is obtained for the monsoonal winds around Sri Lanka. For places of strong local surface forcing, such as over the Sri Lankan central mountain range, a regional model forced by large-scale winds may produce more realistic local rainfall through improved simulation of regional physical processes such as the wind-terrain interaction. For instance, in the L25 simulation, we obtained a better month-to-month evolution of rainfall over Sri Lanka, and the ensemble uncertainty is reduced as well.

In the current study, the RegCM3 is limited to a singledomain and a uniform-grid framework. Our results point to the merits of nesting fine-grid small domains within a coarse-grid large domain or a stretched-grid method (Qian et al. 1999). Besides the attention to model grid and domain sizes, fundamental studies are needed to understand physical processes, and improved physics parameterization schemes are essential for the enhancement of climate modeling and forecast skills (WCRP 2009). Ensemble downscaling by considering variance resulting from different physics parameterization schemes in a regional climate model is also a viable approach (Yang and Arritt 2002). Another issue, which is important but has not been studied here, is the influence of the regional variability of SST. High-frequency SSTs (weekly or daily) may also contribute to weather-within-climate information (such as dry or wet spells and intraseasonal oscillations) and its use is likely to improve downscaling performance. An atmosphere-ocean coupled regional climate model is a desirable tool to study these multiscale processes and their influence on the quality of regional climate downscaling, especially in monsoonal regions with complex topography. These aspects deserve further investigation.

Acknowledgments. We wish to thank Drs. Filippo Giorgi, Xunqiang Bi, Jeremy Pal, and other members in the Abdus Salam ICTP Physics for Weather and Climate Group, the developers of RegCM3. The Max-Planck Institute for Meteorology (Hamburg, Germany) kindly made the ECHAM4.5 available to the International Research Institute for Climate and Society (IRI) at Columbia University. Thanks also to Huilan $\mathrm{Li}$ and Sara Rauscher for processing ECHAM GCM outputs. We also acknowledge the use of TRMM precipitation data. We acknowledge the use of observational data from the Sri Lanka Department of Meteorology, Indian Department of Meteorology and other agencies, and assistance in data processing by the Foundation for Environment, Climate, and Technology. Constructive suggestions by two anonymous reviewers helped to improve the manuscript greatly. The IRI represents a cooperative agreement between the NOAA Office of Global Programs and Columbia University. This paper is funded by a grant/cooperative agreement from the National Oceanic and Atmospheric Administration, NA05OAR4311004. The views expressed herein are those of the authors and do not necessarily reflect the views of NOAA or any of its subagencies. 


\section{REFERENCES}

Alexandru, A., R. de Elia, and R. Laprise, 2007: Internal variability in regional climate downscaling at the seasonal scale. Mon. Wea. Rev., 135, 3221-3238.

Anthes, R. A., Y.-H. Kuo, E.-Y. Hsie, S. Low-Nam, and T. W. Bettge, 1989: Estimation of skill and uncertainty in regional numerical models. Quart. J. Roy. Meteor. Soc., 115, 763-806.

Barnston, A. G., S. J. Mason, L. Goddard, D. G. DeWitt, and S. E. Zebiak, 2003: Multimodel ensembling in seasonal climate forecasting at IRI. Bull. Amer. Meteor. Soc., 84, 1783-1796.

Bhaskaran, B., R. G. Jones, J. M. Murphy, and M. Noguer, 1996: Simulations of the Indian summer monsoon using a nested regional climate model: Domain size experiments. Climate Dyn., 12, 573-587.

Chandimala, J., and L. Zubair, 2006: Predictability of streamflow and rainfall for water resources management in Sri Lanka. J. Hydrol., 335, 303-312.

Chang, C.-P., Z. Wang, J. McBride, and C. Liu, 2005: Annual cycle of Southeast Asia-Maritime Continent rainfall and the asymmetric monsoon transition. J. Climate, 18, 287-301.

Dickinson, R. E., R. M. Errico, F. Giorgi, and G. T. Bates, 1989: A regional climate model for the western United States. Climatic Change, 15, 383-422.

— A. Henderson-Sellers, and P. J. Kennedy, 1993: BiosphereAtmosphere Transfer Scheme (BATS) version 1e as coupled to the NCAR community climate model. NCAR Tech. Note NCAR/TN-387+STR, 72 pp.

Fox-Rabinovitz, M. S., E. H. Berbery, L. L. Lakacs, and R. C. Govindaraju, 2005: A multiple ensemble simulations of the U.S. climate with a stretched-grid GCM. Mon. Wea. Rev., 133, 2505-2525.

Giorgi, F., and L. O. Mearns, 1999: Introduction to special section: Regional climate modeling revisited. J. Geophys. Res., 104 (D6), 6335-6352.

_ - and X. Bi, 2000: A study of internal variability of a regional climate model. J. Geophys. Res., 105, 29 503-29 521.

— M. R. Marinucci, and G. T. Bates, 1993a: Development of a second generation regional climate model (RegCM2). Part I: Boundary layer and radiative transfer processes. Mon. Wea. Rev., 121, 2794-2813.

,-- , and $-1993 \mathrm{~b}$ : Development of a second generation regional climate model (RegCM2). Part II: Convective processes and assimilation of lateral boundary conditions. Mon. Wea. Rev., 121, 2814-2832.

Goddard, L., A. G. Barnston, and S. J. Mason, 2003: Evaluation of the IRI's "Net Assessment" seasonal climate forecasts: 1997 2001. Bull. Amer. Meteor. Soc., 84, 1761-1781.

Grell, G. A., 1993: Prognostic evaluation of assumptions used by cumulus parameterizations. Mon. Wea. Rev., 121, 764-787.

Hastenrath, S., and D. Polzin, 2004: Dynamics of the surface wind field over the equatorial Indian Ocean. Quart. J. Roy. Meteor. Soc., 130, 503-517.

Holtslag, A. A. M., E. I. F. de Bruijn, and H.-L. Pan, 1990: A highresolution air mass transformation model for short-range weather forecasting. Mon. Wea. Rev., 118, 1561-1575.

Kalnay, E., and Coauthors, 1996: The NCEP/NCAR 40-Year Reanalysis Project. Bull. Amer. Meteor. Soc., 77, 437-471.

Kiehl, J. T., J. J. Hack, G. B. Bonan, B. A. Boville, B. P. Briegleb, D. L. Williamson, and P. J. Rasch, 1996: Description of the NCAR Community Climate Model (CCM3). NCAR Tech. Note NCAR/TN-420+STR, 152 pp.
Kummerow, C., and Coauthors, 2001: The evolution of the Goddard profiling algorithm (GPROF) for rainfall estimation from passive microwave sensors. J. Appl. Meteor., 40, 1801-1820.

Laprise, R., 2008: Regional climate modelling. J. Comput. Phys., 227, 3641-3666.

-, and Coauthors, 2008: Challenging some tenets of regional climate modelling. Meteor. Atmos. Phys., 100, 3-22.

Leduc, M., and R. Laprise, 2009: Regional climate model sensitivity to domain size. Climate Dyn., 32, 833-854.

Leung, L. R., S. J. Ghan, Z. C. Zhao, Y. Luo, W.-C. Wang, and H.-L. Wei, 1999: Intercomparison of regional climate simulations of the 1991 summer monsoon in eastern Asia. $J$. Geophys. Res., 104 (D6), 6425-6454.

Li, S., L. Goddard, and D. G. DeWitt, 2008: Predictive skill of AGCM seasonal climate forecasts subject to different SST prediction methodologies. J. Climate, 21, 2169-2186.

Lorenz, E. N., 1963: Deterministic nonperiod flow. J. Atmos. Sci., 20, 130-141.

Lyon, B., L. Zubair, V. Ralapanawe, and Z. Yahiya, 2009: Finescale evaluation of drought hazard for tropical climates. J. Appl. Meteor. Climatol., 48, 77-88.

Mason, S. J., and L. Goddard, 2001: Probabilistic precipitation anomalies associated with ENSO. Bull. Amer. Meteor. Soc., 82, 619-638.

McGregor, J. L., 1997: Regional climate modelling. Meteor. Atmos. Phys., 63, 105-117.

Moron, V., A. W. Robertson, and J.-H. Qian, 2010: Local versus regional-scale characteristics of monsoon onset and post-onset rainfall over Indonesia. Climate Dyn., 34, 281-299.

Pal, J. S., E. E. Small, and E. A. B. Eltahir, 2000: Simulation of regional scale water and energy budgets: Representation of subgrid cloud and precipitation processes within RegCM. J. Geophys. Res., 105 (D24), 29 579-29 594.

-, and Coauthors, 2007: Regional climate modeling for the developing world: The ICTP RegCM3 and RegCNET. Bull. Amer. Meteor. Soc., 88, 1395-1409.

Palmer, T. N., G. J. Shutts, R. Hadgedorn, F. J. Doblas-Reyes, T. Jung, and M. Leutbecher, 2005: Representing model uncertainty in weather and climate prediction. Annu. Rev. Earth Planet. Sci., 33, 163-193.

Peiris, S., J. Hansen, and L. Zubair, 2008: Use of seasonal climate information to predict coconut production in Sri Lanka. Int. J. Climatol., 28, 103-110.

Qian, J.-H., 2008: Why precipitation is mostly concentrated over islands in the Maritime Continent. J. Atmos. Sci., 65, 14281441.

— modes on beta-planes. Pure Appl. Geophys., 160, 1315-1358.

—, F. Giorgi, and M. S. Fox-Rabinovitz, 1999: Regional stretched grid generation and its application to the NCAR RegCM. J. Geophys. Res., 104, 6501-6513.

_ A. Seth, and S. Zebiak, 2003: Reinitialized versus continuous simulations for regional climate downscaling. Mon. Wea. Rev., 131, 2857-2874.

- W.-K. Tao, and K.-M. Lau, 2004: Mechanisms for torrential rain associated with mei-yu development during SCSMEX1998. Mon. Wea. Rev., 132, 3-27.

Rajeevan, M., J. Bhate, J. D. Kale, and B. Lal, 2005: Development of a High Resolution Daily Gridded Rainfall Data for the Indian Region. Meteor. Monogr., No. 22/2005, India Meteorological Department, $27 \mathrm{pp}$.

Ramage, C. S., 1971: Monsoon Meteorology. International Geophysical Series, Vol. 15, Academic Press, 296 pp. 
Rauscher, S. A., A. Seth, J.-H. Qian, and S. J. Camargo, 2006: Domain choice in an experimental nested modelling prediction system for South America. Theor. Appl. Climatol., 86, 229-246.

Roads, J., and Coauthors, 2003: International Research Institute/ Applied Research Centers (IRI/ARCs) regional model intercomparison over South America. J. Geophys. Res., 108, 4425, doi:10.1029/2002JD003201.

Roeckner, E., and Coauthors, 1996: The atmospheric general circulation model ECHAM4: Model description and presentday climate. Max-Planck-Institut für Meteorologie Rep. 218, Hamburg, Germany, 90 pp.

Seth, A., and F. Giorgi, 1998: The effects of domain choice on summer precipitation simulation and sensitivity in a regional climate model. J. Climate, 11, 2698-2712.

__, M. Rojas, B. Liebmann, and J.-H. Qian, 2004: Daily rainfall analysis for South America from a regional climate model and station observations. Geophys. Res. Lett., 31, L07213, doi:10.1029/ 2003GL019220.

Sun, L., F. H. M. Semazzi, F. Giorgi, and L. Ogallo, 1999: Application of the NCAR regional climate model to eastern Africa. Part II: Simulation of interannual variability of short rains. J. Geophys. Res., 104, 6549-6562.

—, D. F. Moncunill, H. Li, A. D. Moura, F. A. S. Filho, and S. E. Zebiak, 2006: An operational dynamical downscaling prediction system for Nordeste Brazil and the 2002-04 realtime forecast validation. J. Climate, 19, 1990-2007.

Tao, W.-K., Y. Wang, J.-H. Qian, C.-L. Shie, K.-M. Lau, and R. Kakar, 2003: Mesoscale convective systems during SCSMEX: Simulations with a regional climate model and a cloud-resolving model. Weather and Climate Modeling: INDO-U.S. Science and
Technology Forum, V. Singh, S. Basu, and T. N. Krishnamurti, Eds., New Age International, 77-92.

Vannitsem, S., and F. Chome, 2005: One-way nested regional climate simulations and domain size. J. Climate, 18, 229-233.

Wang, Y., L. R. Leung, J. L. McGregor, D.-K. Lee, W.-C. Wang, Y. Ding, and F. Kimura, 2004: Regional climate modeling: Progress, challenges, and prospects. J. Meteor. Soc. Japan, 82 , 1599-1628.

_ - L. Zhou, and K. P. Hamilton, 2007: Effect of convective entrainment/detrainment on simulation of tropical precipitation diurnal cycle. Mon. Wea. Rev., 135, 567-585.

WCRP, 2009: World Modelling Summit for Climate Prediction. Workshop Rep. WCRP 131, WMO/TD 1468, 31 pp.

Wyrtki, K., 1973: An equatorial jet in the Indian Ocean. Science, 181, 262-264.

Xie, S.-P., H. Xu, N. H. Saji, Y. Wang, and W. T. Liu, 2006: Role of narrow mountains in large-scale organization of Asian monsoon convection. J. Climate, 19, 3420-3429.

Yang, Z., and R. W. Arritt, 2002: Tests of a perturbed physics ensemble approach for regional climate modeling. J. Climate, $\mathbf{1 5}$, 2881-2896.

Zhou, L., and Y. Wang, 2006: Tropical Rainfall Measuring Mission observation and regional model study of precipitation diurnal cycle in the New Guinean region. J. Geophys. Res., 111, D17104, doi:10.1029/2006JD007243.

Zubair, L., 2002: El Niño-Southern Oscillation influences on rice production in Sri Lanka. Int. J. Climatol., 22, 249-260.

_- M. Siriwardhana, J. Chandimala, and Z. Yahiya, 2008: Predictability of Sri Lankan rainfall based on ENSO. Int. J. Climatol., 28, 91-101. 